\title{
Observations of Irminger Sea Anticyclonic Eddies
}

\author{
Xue FAn AND Uwe SEND \\ Scripps Institution of Oceanography, University of California, San Diego, La Jolla, California \\ PIERRE TESTOR \\ L'OCEAN, Université Pierre and Marie Curie, Paris, France \\ JOHANNES KARSTENSEN \\ IFM-GEOMAR, Kiel, Germany \\ PASCALE LHERMINIER \\ Ifremer, Plouzané, France
}

(Manuscript received 15 August 2011, in final form 2 January 2013)

\begin{abstract}
Mesoscale anticyclonic eddies in the Irminger Sea are observed using a mooring and a glider. Between 2002 and 2009, the mooring observed 53 anticyclones. Using a kinematic model, objective estimates of eddy length scales and velocity structure are made for 16 eddies. Anticyclones had a mean core diameter of $12 \mathrm{~km}$, and their mean peak observed azimuthal speed was $0.1 \mathrm{~m} \mathrm{~s}^{-1}$. They had core salinities and potential temperatures of 34.91-34.98 and $4.48^{\circ}-5.34^{\circ} \mathrm{C}$, respectively, making them warm and salty features. These properties represent a typical salinity anomaly of 0.03 and a temperature anomaly of $0.28^{\circ} \mathrm{C}$ from noneddy values. All eddies had small $(\ll 1)$ Rossby numbers. In 2006, the glider observed two anticyclones having diameters of about $20 \mathrm{~km}$ and peak azimuthal speeds of about $0.3 \mathrm{~m} \mathrm{~s}^{-1}$. Similar salinity anomalies were detected throughout the Irminger Sea by floats profiling in anticyclones. Two formation regions for the eddies are identified: one to the west of the Reykjanes Ridge and the other off the East Greenland Irminger Current near Cape Farewell close to the mooring. Observations indicate that eddies formed in the former region are larger than eddies observed at the mooring. A clear increase in eddy salinity is observed between 2002 and 2009. The observed breakup of these eddies in winter implies that they are a source of salt for the central gyre. The anticyclones are similar to those found in both the Labrador Sea and Norwegian Sea, making them a ubiquitous feature of the subpolar North Atlantic basins.
\end{abstract}

\section{Introduction}

The Irminger Sea (shown in Fig. 1) forms part of the transition zone between the warmer, more saline subtropical North Atlantic and the colder, fresher Arctic waters. The Irminger Current brings warm, salty water from the south into the Irminger Sea along the west side of the Reykjanes Ridge (see Schott et al. 2004; Lherminier et al. 2010; Daniault et al. 2011). At $65^{\circ} \mathrm{N}$, the current turns

Corresponding author address: Xue Fan, Scripps Institution of Oceanography, Mailcode 0208, 9500 Gilman Drive, La Jolla, CA 92093.

E-mail: xufan@ucsd.edu and flows south along the Greenland coast, becoming the East Greenland Irminger Current (EGIC). At Cape Farewell, the EGIC wraps around Greenland, and part of the EGIC transport is retroflected back toward the center of the Irminger Sea (Holliday et al. 2007).

Like in other basins in the North Atlantic, eddies in the Irminger Sea are often noted for their strong signal in in situ measurements (e.g., Våge et al. 2011; De Jong 2010; De Jong et al. 2012). In the neighboring Labrador Sea (see Fig. 1), it has been shown that a certain type of eddy [called Irminger Current Anticyclones (ICAs)] is responsible for between $25 \%$ and $100 \%$ of the heat needed to balance the surface heat loss during winter convection (Lilly et al. 2003; Katsman et al. 2004; Hátún 


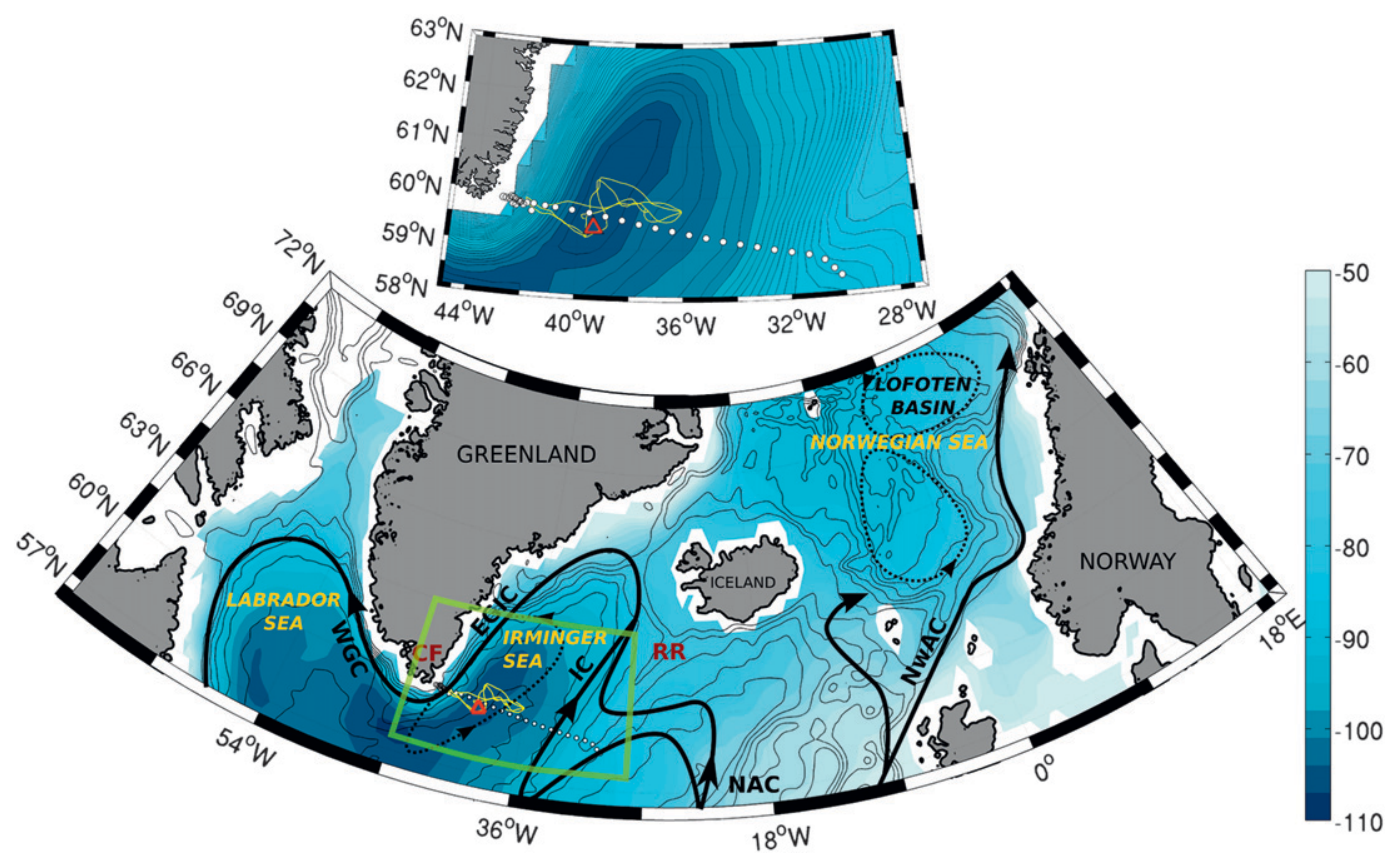

FIG. 1. Map of basins and current systems of study area. Solid black pathways show a schematic of the general upper currents adapted from Schott et al. (2004), Köhl (2007), and Daniault et al. (2011). The major currents are: the West Greenland Current (WGC), East Greenland Irminger Current (EGIC), Irminger Current (IC), North Atlantic Current (NAC), and Norwegian Atlantic Current (NwAC). Dotted black lines show recirculation patterns in the Irminger Sea and Norwegian Sea. Blue colors represent the 1992-2002 mean surface dynamic ocean topography $(\mathrm{cm})$ obtained from Nikolai Maximenko (IPRC) and Peter Niiler (SIO) (Maximenko et al. 2009). Thin black contours represent the bottom topography in 500-m intervals. Geographic features, in red text, are the Reykjanes Ridge (RR), and Cape Farewell (CF). The green line marks the boundaries of the inset. Inset: the yellow track shows the glider path, the red triangle represents the CIS mooring location in the center of the gyre, and the white dots show ship hydrographic stations from the Ovide cruises. Black lines and blue color contours represent the mean dynamic topography (same as in lower figure) to highlight the mooring's location in the center of the lowest surface dynamic topography.

et al. 2007; Rykova et al. 2009) and can be an important contributor to the salt (or freshwater) budget (Hátún et al. 2007; Schmidt and Send 2007). In the Norwegian Sea, anticyclones observed in the Lofoten Basin (see Fig. 1) have been shown to be essential in maintaining the heat balance there (Nilsen and Falck 2006; Köhl 2007; Rossby et al. 2009a). In both the Labrador Sea and Lofoten Basin, eddies have been extensively observed and documented, but an equivalent analysis of eddies in the Irminger Sea does not yet exist, and the potential for eddies in the Irminger Sea to affect budgets has not been explored.

Eddies in the Irminger Sea appear in many observations (e.g., Holliday et al. 2007; De Jong 2010; Daniault et al. 2011; Våge et al. 2011; De Jong et al. 2012), but only a few studies have quantified their size and examined their properties. One study by Krauss (1995) shows energetic eddies in the center of the Irminger gyre having a mean eddy kinetic energy (EKE) four times greater than the mean Irminger Sea kinetic energy. The eddies observed from these shipboard measurements typically have a horizontal scale of $75 \mathrm{~km}$, and an anticyclone is observed with anomalously high salinity and temperature compared to noneddy water found in the Irminger Basin. Another study of eddies by Bruce (1995) focused on cold-core cyclonic eddies observed by satellite and moored current meters. These cyclones, having a diameter of $20-40 \mathrm{~km}$, stayed trapped within the EGIC and did not appear to enter the gyre interior.

This study seeks to add to the present knowledge of eddies in the Irminger Sea. We focus on observations of anticyclonic eddies found in the Irminger Sea for two reasons: first, because they represent a source of heat and salt to the basin and may thus modulate the water mass properties in the Irminger sea, and second, because they appear to be analogous to the anticyclones found in the Labrador and Norwegian Seas, making such eddies a widespread phenomenon in the high-latitude North Atlantic. We present this work in two parts. Using data from a 7-yr mooring time series, a glider, the Argo float 
array, and satellite altimetry, the present Part I focuses on analyzing the properties of the observed anticyclones. A separate manuscript (referred to as Part II) will then seek to quantify the eddy transport of heat and salt by the observed anticyclones and to determine their importance in the heat and salt budgets of the upper waters of the Irminger Sea.

This paper is organized as follows. We describe the data used in section 2. Sections 3 and 4 present the data treatment and observations of properties of anticyclones obtained from the 7-yr mooring time series and the glider, respectively. Basin-wide eddy observations are presented in section 5 , and the origin of the eddies is examined in section 6. A comparison with Labrador Sea and Lofoten Basin anticyclones is made in section 7, and a discussion follows in section 8 .

\section{Data}

\section{a. Mooring}

The Central Irminger Sea (CIS) mooring is located nominally at $59.7^{\circ} \mathrm{N}, 39.7^{\circ} \mathrm{W}$ (marked by the red triangle in Fig. 1). It was placed in the region of lowest surface dynamic height corresponding to the center of the gyre by this measure. The mooring has been in operation since September 2002. Primary instruments include Seabird MicroCATs which record temperature, conductivity, and pressure at approximately 14 depths between the surface and $1500 \mathrm{~m}$ with a 20-min temporal resolution. Starting in 2003, currents in the upper $800 \mathrm{~m}$ of the water column were measured using a combination of a 300-kHz (upward) and a 150-kHz (downward) Acoustic Doppler Current Profiler (ADCP). The current observations were complemented by rotary current meters at 1000- and 2400-m depth. Biogeochemical sensors measured nitrate, chlorophyll-a fluorescence, and carbon dioxide at $45 \mathrm{~m}$. Only the physical data are used in this study. Table 1 shows a representative list of instrumentation used at various depths.

The physical data from the CIS mooring instrumentation were calibrated each time the mooring was serviced. The mooring data contain some gaps owing to equipment failure. The data used in this study span from late 2002 to mid-2009 and are quality controlled. A detailed description of the quality control procedures applied to the CIS mooring data is given in Karstensen (2005). The parameters (temperature, salinity, and ADCP velocities) were linearly interpolated onto a common time axis of one-hour intervals. Using the time-varying pressure signal and mooring instrument placement, parameters were linearly interpolated onto a constant 20-dbar pressure grid. Additionally, the
TABLE 1. CIS Mooring configuration and instrumentation example taken from the CIS third deployment (2004). Note that not every MicroCAT has a pressure sensor, and pressures are interpolated for measurements that do not have their own pressure sensor. The second MicroCAT is part of a slack surface telemetry unit which does not have tension pulling the wire vertical. Here, the measurements $S, T$, and $P$ are salinity, temperature, and pressure, respectively. In addition, horizontal velocity measurements are denoted by $U$ and $V$, and vertical velocity by $W$.

\begin{tabular}{cll}
\hline \hline Nominal depth & \multicolumn{1}{c}{ Instrument } & \multicolumn{1}{c}{ Measurement } \\
\hline $10 \mathrm{~m}$ & SBE MicroCAT IM & $S, T$ \\
$10-30 \mathrm{~m}$ & SBE MicroCAT IMP & $S, T, P$ \\
$70 \mathrm{~m}$ & SBE MicroCAT IM & $S, T$ \\
$109 \mathrm{~m}$ & SBE MicroCAT IM & $S, T$ \\
$150 \mathrm{~m}$ & Teledyne-RDI & $U, V, W$ velocities \\
& Workhorse (upward) & \multicolumn{1}{c}{$0-150 \mathrm{~m}, P$} \\
$153 \mathrm{~m}$ & Teledyne-RDI Longranger & $150-720 \mathrm{~m}, P$ \\
& ADCP (downward) & \\
$155 \mathrm{~m}$ & SBE MicroCAT IM & $S, T$ \\
$197 \mathrm{~m}$ & SBE MicroCAT IM & $S, T$ \\
$267 \mathrm{~m}$ & SBE MicroCAT IMP & $S, T, P$ \\
$372 \mathrm{~m}$ & SBE MicroCAT IM & $S, T$ \\
$548 \mathrm{~m}$ & SBE MicroCAT IMP & $S, T, P$ \\
$748 \mathrm{~m}$ & SBE MicroCAT IM & $S, T$ \\
$998 \mathrm{~m}$ & SBE MicroCAT IMP & $S, T, P$ \\
$1004 \mathrm{~m}$ & Aanderaa RCM-8 AVTP & $T, P$ and $U, V$ point \\
& & velocities \\
$1245 \mathrm{~m}$ & SBE MicroCAT IMP & $S, T, P$ \\
$1496 \mathrm{~m}$ & SBE MicroCAT IM & $S, T$ \\
$2283 \mathrm{~m}$ & McLean Sediment Trap & Sediment \\
& & accumulation \\
$2327 \mathrm{~m}$ & Aanderaa RCM-8 AVT & $T$ and $U, V$ point \\
& & velocities \\
\hline
\end{tabular}

ADCP data were low-pass-filtered using an Equiripple filter to suppress features with frequencies larger than 1 day $^{-1}$ (thus removing inertial waves and tides).

\section{b. Glider}

We use data from the Spray glider mission executed in 2006 under the Marine Environment and Security for the European Area (MERSEA) project. The glider path is shown in yellow in Fig. 1. The Spray glider is an autonomous underwater vehicle that uses changes in buoyancy to propel itself through the water column while taking profiles of temperature, pressure, and salinity. While at the surface, the Spray glider transmits its GPS position fix and dive data through the Iridium satellite system. The GPS fixes are used to calculate an absolute depth-averaged velocity using dead reckoning; from here on, when the phrase "glider velocity" is used, a velocity averaged over the depth of the dive is implied. A detailed description of the Spray glider can be found in other publications (e.g., Sherman et al. 2001; Rudnick et al. 2004). The Spray glider used here sampled from the surface to $1000-\mathrm{m}$ depth, making dives between 
3 and $5 \mathrm{~km}$ apart horizontally and taking about $5 \mathrm{~h}$ between each surfacing.

\section{c. Satellite altimetry}

For satellite altimetry data, the gridded merged Archiving, Validation, and Interpretation of Satellite Oceanographic data (AVISO) product (described in Picot et al. 2003) is used in this study. The sea surface height anomaly is an objectively mapped estimate calculated relative to a mean sea surface averaged over 1992-2005. This product has a time resolution of 7 days and comes corrected for various effects [wet and dry troposphere, inverse barometer, electromagnetic bias, and ocean tides; see Picot et al. (2003) for more details]. The merged product is so called because it is a combination of the Ocean Topography Experiment (TOPEX)/ Poseidon, Jason-1, EnviSat, and Geosat satellites. Both latitude and longitude coordinates are mapped onto a $1 / 3^{\circ}$ Mercator projection while accounting for longwavelength errors (Ducet et al. 2000).

A dataset derived from the satellite altimetry-merged product results from Chelton et al. (2007); it identifies and tracks coherent mesoscale eddies globally from 1992 to 2008. Details of the eddy-tracking algorithm can be found from Chelton et al. (2011). The method that produced the dataset in this study will be referred to as the "Chelton" algorithm. It should be noted that the gridded satellite altimetry product dampens eddy signals smaller than $40 \mathrm{~km}$ in size (Chelton et al. 2011) and appears to have large uncertainties near the EGIC region (Gourcuff et al. 2011).

\section{d. Argo}

Argo floats within the Irminger Sea provide profiles of temperature and salinity from the surface to 2000-m depth approximately every 10 days. These floats drift at $1000 \mathrm{~m}$ for about 10 days, then descend to $2000 \mathrm{~m}$ and rise to the surface over $6 \mathrm{~h}$, collecting measurements on ascent. At the surface, data are transmitted and the float's location is determined. The float then dives back to $1000 \mathrm{~m}$ to repeat its 10 -day cycle. The data from these floats are available through the International Argo Project and can be found through the Global Ocean Data Assimilation Experiment (GODAE) project server (http://www.usgodae.org/argo/argo.html). Only delayed-time quality-controlled data were used in this study.

\section{e. "Ovide" ship sections}

The Ovide cruises were carried out as described in detail by Lherminier et al. (2007, 2010). They were performed on the R/V Thalassa between June and July of 2002, 2004, and 2006. Part of their cruise track, shown with white circles in Fig. 1, crosses the Irminger Basin from the coast of Greenland to beyond the Reykjanes Ridge. At each of the approximately 30 stations in the Irminger Sea, measurements included conductivity, temperature, and pressure via a Neil Brown Mark III CTD probe. Salinity was calibrated with seawater samples analyzed on board.

\section{f. 15-m-drogued drifters}

Two drifter tracks are used to illustrate different flow situations in this study. They were obtained from the public archives of the Global Drifter Data Assembly Center at the National Oceanographic and Atmospheric Administration's (NOAA's) Atlantic Oceanographic and Meteorological Laboratory (AOML). Drifters were drogued at $15 \mathrm{~m}$ below the surface float and were tracked by satellite positioning. Drifter details, processing, and quality control at AOML are described in Hansen and Herman (1989) and Hansen and Poulain (1996).

\section{Anticyclones observed at the CIS Mooring}

\section{a. Methods}

Figure 2 shows the mooring salinity time series with potential density contours superimposed. Here, both salinity and density are smoothed with a 3-day running mean at each pressure level. One first notices a change in overall color from cooler to warmer tones from 2002 to 2009 , representing an overall increase in salinity over the dataset. The surface to $1000-\mathrm{m}$ mean salinity increases $5.7 \times 10^{-3} \mathrm{yr}^{-1}$ over the time series. This is within the $1.15-7.3 \times 10^{-3} \mathrm{yr}^{-1}$ rate of salinity increase described by others in the Irminger Sea between 2003 and 2007 (Sarafanov et al. 2007; De Jong 2010). The trend is also the same magnitude as the general salinification observed in the Labrador Sea and Nordic Seas beginning in the 2000s (see Falina et al. 2007; Sarafanov et al. 2007; Holliday et al. 2008; Louarn et al. 2009). This interannual variability is not the focus of the present paper.

The next obvious scale of variability is the displacement of isopycnals often corresponding to marked changes in salinity and usually lasting on the order of 10 days. These features appear less frequently between January and May, a period of strong winter surface forcing. They also appear to undergo a change in properties over the time series: in Fig. 2, their salinity representation evolves from light red in 2002 to deep red and white in 2009. This signifies a salinifying trend of the features themselves, an aspect that will be addressed in a later section. 

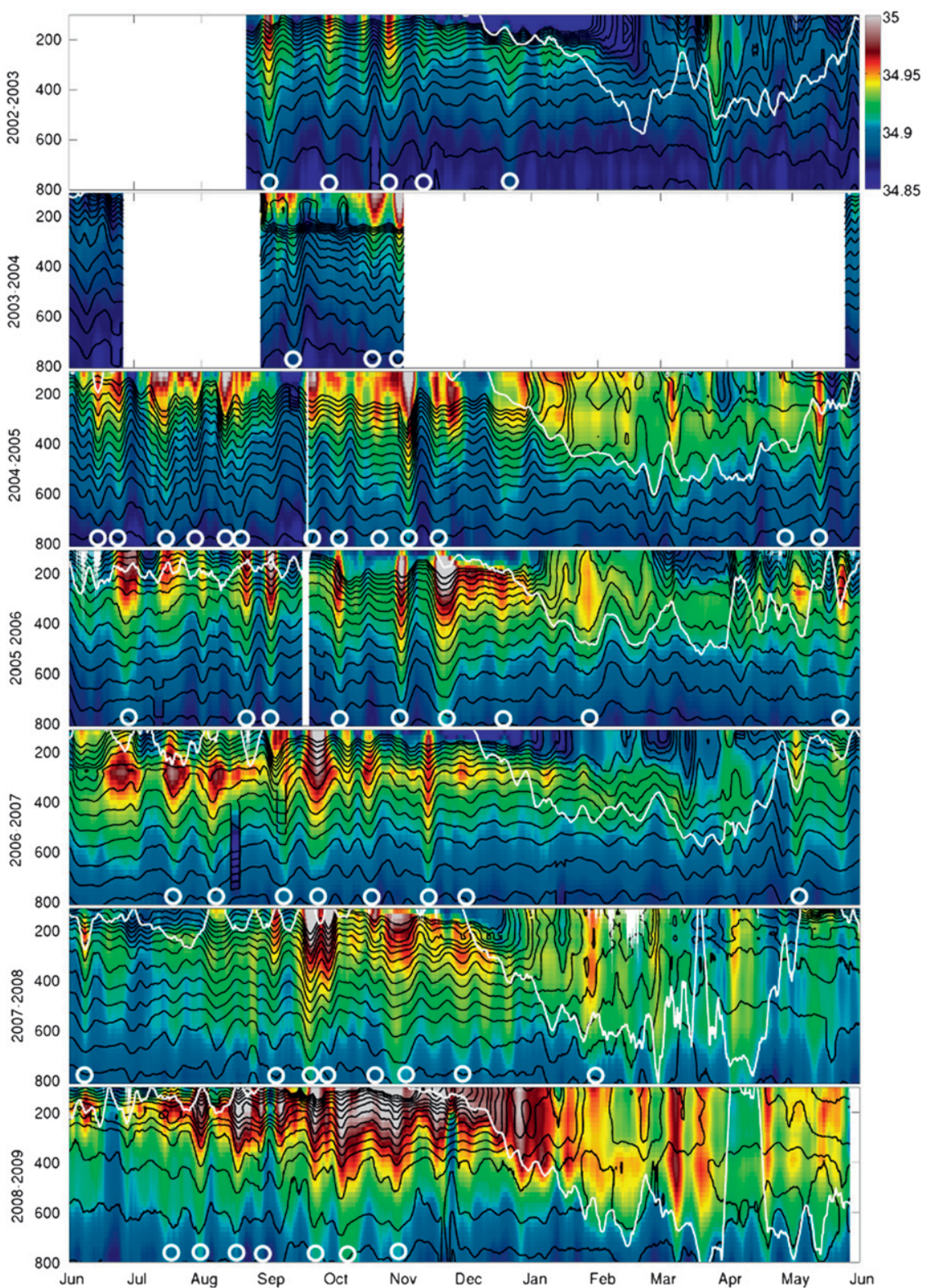

FIG. 2. Color depth-time display showing salinity from 7 years of CIS mooring deployment. Black lines are potential density contours, plotted with a spacing of $0.01 \mathrm{~kg} \mathrm{~m}^{-3}$. The white line represents the mixed layer depth calculated by a threshold difference of $0.5^{\circ} \mathrm{C}$ from the surface temperature. A running mean is applied to the data at each pressure level with a 3-day time window. Identified anticyclones are indicated by white circles found at the bottom of their profiles. This includes eddies whose cores were not transected as well as "likely" anticyclones (9 total), which had a typical salinity anomaly signature and turning velocities, but an atypical hodograph.

Four possibilities exist to explain these features: (i) internal wave motion, (ii) meanders from the nearby EGIC, (iii) fresh-core cyclonic eddies (doming isopycnals with lower, or more blue, salinity), or (iv) saltycore anticyclonic eddies (bowl-shaped isopycnals with higher, or more red, salinity). We use hodographs produced from the mooring ADCP to determine that these features are (iv), salty-core anticyclonic eddies. Following the analyses of Lilly and Rhines (2002), the presence of an eddy event moving past a mooring produces a hodograph with D-shaped curves, closed circles, or straight lines, resulting from a closed vortex's turning 

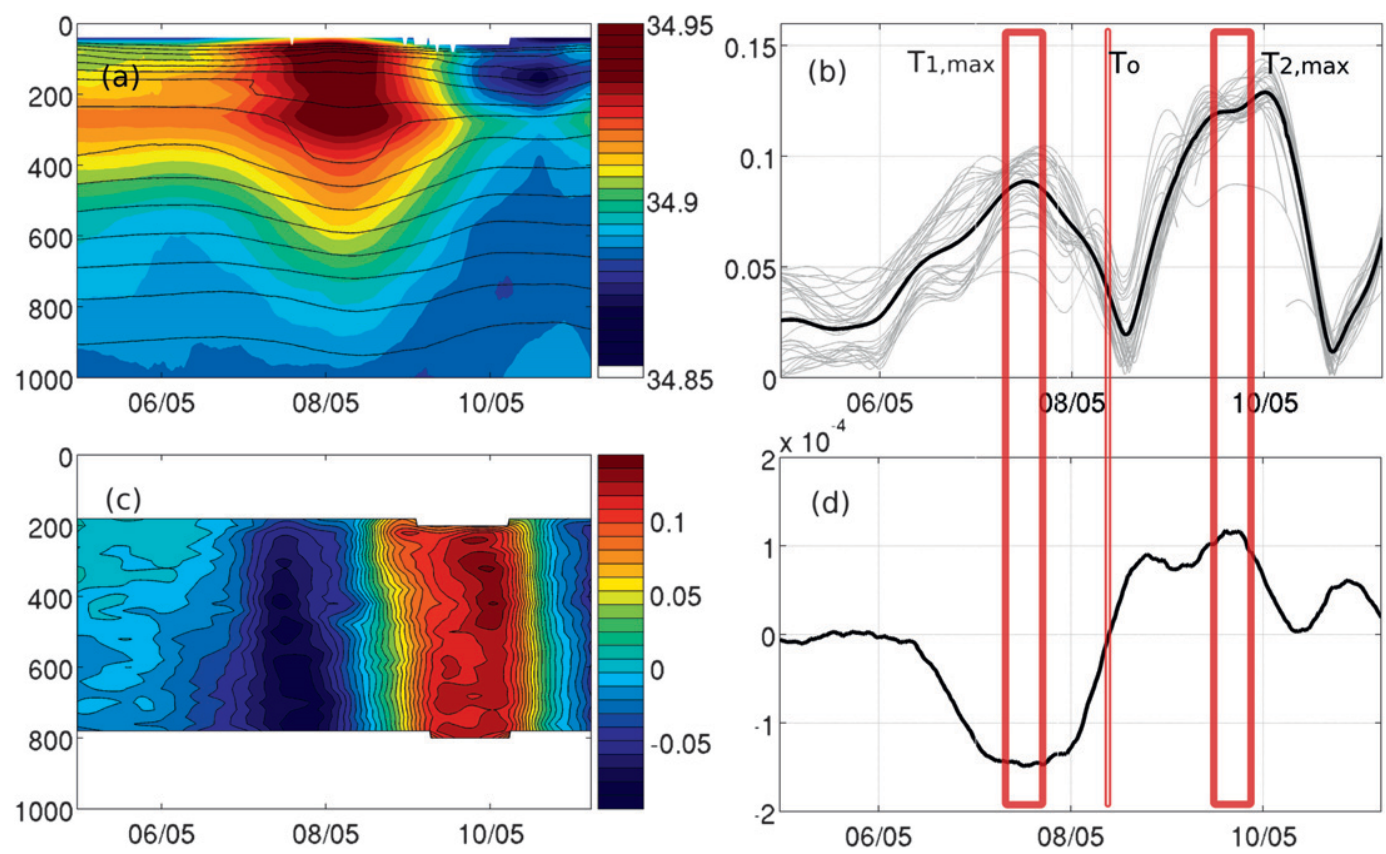

FIG. 3. An example of one mooring eddy and the method to determine $V_{\max }$ and $T_{o}$. (a) Salinity in color contours with black potential density contours (intervals of $0.01 \mathrm{~kg} \mathrm{~m}^{-3}$, starting from 1027.74 at the bottom contour). (b) Observed magnitude of velocity signal $\left(\mathrm{m} \mathrm{s}^{-1}\right)$ from all levels during eddy passing (thin gray lines) and their column average (thick black line). (c) Observed velocity signal perpendicular to the advection direction ( $\mathrm{m} \mathrm{s}^{-1}$ ) plotted against depth and time. (d) Depth-averaged $d p / d t\left(\mathrm{dbar} \mathrm{s}^{-1}\right)$ derived from the density data. The two thick red boxes indicate the minimum and maximum points used in the algorithm, and the thin red box shows the location of $T_{o}$, where $d p / d t$ crosses zero.

velocities. At almost all of the high salinity anomalies corresponding to bowl-shaped isopycnals, these hodograph shapes are indeed observed. Internal wavelike motions would not create such a turning of velocities, nor would a meander from the EGIC (explored again in a later section), ruling out (i) and (ii). Also, features with doming isopycnals showed no hodograph shapes corresponding to cyclonic eddies. We are left with choice (iv), that most of this variability is caused by anticyclonic eddies with a high salinity core.

Our objective is now to estimate the eddy size and create a census of observed events. We present a method to estimate the eddy radius $R_{\max }$ and accompanying maximum azimuthal velocity $V_{\max }$, employing to the model used by Hátún et al. (2007). This model assumes the eddy is a vortex in solid body rotation, an observed characteristic for anticyclonic eddies in previous in situ studies (e.g., Newton et al. 1974; Armi et al. 1989; Pingree and Le Cann 1992; Hátún et al. 2007). Thus, the azimuthal velocity $V$ grows linearly with the radial distance $r$ as

$$
V(r)=\frac{V_{\max }}{R_{\max }} r, \quad r<R_{\max } .
$$

Beyond the core radius $\left(r>R_{\max }\right), V$ will decay with radial distance. Because we do not use observations beyond $R_{\max }$ in our data treatment, the shape of this decay does not change our result.

We determine whether a high-salinity feature is an eddy, and then we estimate $R_{\max }$ and accompanying maximum azimuthal velocity $V_{\max }$, using the model from (1). The steps to achieve this are as follows.

\section{1) IDENTIFY EDDY OCCURRENCES}

We isolate events with high salinity anomalies coinciding with dipping isopycnals (an example of which is shown in Fig. 3a). Data encompassing three days before the first detection of the salinity anomaly and three days after its last detection are used in the next steps. An anomaly is considered significant when the salinity exceeds the mean plus one standard deviation of the average salinity in a given year between 200- and 300-m depth (the layer where the highest salinities are typically found). Values for this salinity threshold ranged from 34.91 to 34.99 . The presence of an eddy event is then verified from hodographs following Lilly and Rhines (2002). D-shaped hodographs indicate observations where $r<R_{\max }$ (the eddy core is crossed), circles imply 
observations where all $r>R_{\max }$, and straight lines occur only when the center of the eddy is crossed. Events with other hodograph shapes are not considered further in the eddy analysis. In the case where the eddy core is crossed, two maxima are observed in the ADCP velocity speed, and only one maximum is observed in crossings of the eddy periphery. The eddy events (core and peripheral encounters) are shown with white circles in Fig. 2 and are all used in eddy counts and property statistics, but only the events which cross the core can be used to estimate $R_{\max }$ and $V_{\max }$ with the method developed here.

\section{2) FIND THE DIRECTION OF EDDY TRANSLATION PAST THE MOORING}

Following Lilly et al. (2003, hereafter L03), this can be done by identifying the two time points $T_{1, \max }$ and $T_{2, \max }$ when the eddy core $R_{\max }$ crosses the mooring, and extracting the observed velocities at those times $\left(\mathbf{V}_{1 \text {,maxtot }}\right.$ and $\mathbf{V}_{2 \text {,maxtot }}$ ). These observed velocities are averaged from 200- to 800-m depth (a layer that incorporated most of the eddy velocity signal). Here we depart from L03 by not using the velocity observations to determine $T_{1, \max }$ and $T_{2, \max }$ because the velocities in our dataset are asymmetric and not centered on the eddy high salinity core. This is likely due to barotropic circulations and noneddy flows. Instead, we prefer to find the times when the maximum isopycnal slope or horizontal pressure gradient passes the mooring, using the time derivative of pressure $d p / d t$ as a proxy for the horizontal pressure gradient. Here, $d p / d t$ is derived from density data using hydrostatic balance and averaged over 200 $800 \mathrm{~m}$. For an anticyclone we expect the $d p / d t$ signal to move from negative, through zero, to positive as the eddy core is crossed. From this, we determine $T_{1, \max }$ (minimum $d p / d t$ ), $T_{o}$ (where the mooring comes closest to the eddy center, when $d p / d t$ crosses zero), and $T_{2, \max }$ (maximum $d p / d t$ ). These quantities are shown in an example eddy in Figs. $3 \mathrm{~b}$ and $3 \mathrm{~d}$. The velocities $\mathbf{V}_{1 \text {,maxtot }}$ and $\mathbf{V}_{2 \text {,maxtot }}$ are observed at the times $T_{1, \text { max }}$ and $T_{2 \text {,max }}$ and are used in the translation direction estimate. As explained in L03, the eddy translation direction is perpendicular to the vector difference $\mathbf{V}_{1 \text {,maxtot }}-\mathbf{V}_{2 \text {,maxtot }}$.

\section{3) Calculate the translation SPeEd of EDDY PAST THE MOORING}

We find a depth-independent translation speed such that the observed velocity shear and the observed rate of change of density will be in thermal wind balance. This method differs from L03, who balance the absolute velocities and the rate of change of pressure. For ease of notation we use a local rotated coordinate system where $x$ is the direction of translation, estimated in the previous step. Thermal wind balance is then defined by

$$
f \frac{\partial v}{\partial z}=-\frac{g}{\rho_{o}} \frac{\partial \rho}{\partial x} .
$$

Here, $f$ is the Coriolis frequency $\left(f=1.26 \times 10^{-4} \mathrm{~s}^{-1}\right.$ at $\left.60^{\circ} \mathrm{N}\right), v$ is the velocity component perpendicular to the direction of $x, z$ is the vertical direction, $g$ is $9.8 \mathrm{~m} \mathrm{~s}^{-2}$, $\rho$ is the potential density, and $\rho_{o}$ is a reference potential density (taken as the average potential density over all depths over the time series). This departs from L03 also in that we neglect the cyclostrophic term, which is small for our eddies. As mentioned, L03 suggest reconstructing the pressure field by vertically integrating the density field and comparing this to observed velocity magnitudes. We opt to balance only the horizontal density gradient field with the vertical shear because the barotropic component of the eddy flow is large (visible in Fig. 3c). It would therefore be incorrect, in our case, to balance observed absolute velocities with pressure gradients referenced to some depth, as in L03. Using (2), we estimate $\partial x$ as $\Delta x$, the size of the eddy core transect. We then define $U$ as the magnitude of the translation velocity. Using $\Delta x=-U \Delta t$, where $\Delta t=\left|T_{o}-T_{1,2, \max }\right|$, we have an estimate of $U$. Comparing the two estimates of $U$ for each half of the transected eddy (at $T_{1, \max }$ and $T_{2, \max }$ ) gives an indication of the robustness of the results.

\section{4) Generate Velocities due to edDy FLOW ONLY}

Now we assume, as done in L03, that the movement of the eddy past the mooring is due to a depth-independent translation with magnitude $U$ and direction determined by the previous steps; this translation is removed from the observed velocities to obtain a velocity signal representing eddy flow only. This yields our estimate of the true maximum eddy speed $V_{\max }$, for which we obtain two values, $V_{1 \text {,max }}$ and $V_{2 \text {,max }}$, representing estimates at $T_{1, \max }$ and $T_{2, \max }$, respectively.

\section{$5)$ ESTIMATE $R_{\text {MAX }}$ USING A LEAST SQUARES FIT OF EDDY VELOCITIES TO A SOLID BODY MODEL}

We take a step further than L03 here to estimate the actual eddy radius. Recall the solid body model described by (1). In our rotated frame, $x$ is in the direction of translation, and $y$ is perpendicular to this. We obtain the following equations describing the mooring velocity components:

$$
u_{\mathrm{fit}}=\frac{V_{\max }}{R_{\max }} y_{o}+U \text { and }
$$




$$
v_{\text {fit }}=-\frac{V_{\max }}{R_{\max }} X
$$

where $X=x_{o}-U t, t$ is the time vector, and $y_{o}$ is the offset in the $y$-direction (constant in the rotated frame). We know $U, V_{\max }$, and $x_{o}=-U T_{1, \max }$. The remaining unknowns are $R_{\max }$ and $y_{o}$, and are determined using the Nelder-Mead method (see Nelder and Mead 1965) to minimize the sum of the squared misfit between eddy model velocities $\left(u_{\mathrm{fit}}, v_{\mathrm{fit}}\right)$ and the observed velocities over the period between $T_{1, \max }$ and $T_{2 \text {,max }}$ (where the eddy is expected to exhibit solid body rotation).

The estimates of $U, V_{\max }$, and $R_{\max }$ come from the average of the two segments of the eddy crossings; the difference between the estimates at these two segments gives an idea of the asymmetry and the error of the estimates. The root-mean-squared deviation was $\pm 0.017 \mathrm{~m} \mathrm{~s}^{-1}$ for $U$ and $\pm 0.010 \mathrm{~m} \mathrm{~s}^{-1}$ for $V_{\max }$, which meant a variability of $\pm 4.5 \mathrm{~km}$ for the $R_{\max }$ estimate. Results were compared with the estimates performed using the cyclogeostrophic method from L03; our method results in a consistently larger estimate of $U$ compared to their method. It would be expected that the L03 method underestimates the translation speed for our eddies due to the nonnegligible barotropic flow which is missing in their calculation of $d p / d t$. This would lead to an underestimate of the eddy sizes $\left(R_{\max }\right)$. The sensitivity to the form of (1) was tested by performing the previous steps using a Gaussian velocity distribution with the form $V(r)=V_{\max } \exp \left\{\left[\left(r-R_{\max }\right) /\left(R_{\max } / 2\right)\right]^{2}\right\}$. The fit determined $R_{\max }$ to be, on average, $15 \%$ higher than $R_{\max }$ resulting from (1), which is well within the range of the $\pm 4.5-\mathrm{km}$ variability of the $R_{\max }$ estimate. This suggests that the $R_{\max }$ fit is sufficiently insensitive to the exact model used in the minimization.

\section{b. Results}

Using the above method, a total of 76 high salinity anomalies coinciding with dipping isopycnals were found between September 2002 and June 2009. Of these, 54 had sufficient velocity and density data to proceed further. Forty-four events were identified as anticyclones from their hodograph and the direction with which their velocities turned and are marked by white circles in Fig. 2. To revisit an earlier discussion, these features cannot be meanders from the nearby EGIC not only because their hodographs show the shapes produced only by anticyclones, but because of the following density gradient argument. We compare the horizontal density gradients observed in the mooring eddies and the Ovide stations that sampled in the EGIC. The repeated Ovide transects all show the EGIC having about half the horizontal density gradient of that observed in the eddies. To create the same degree of isopycnal dipping in the same time period as an eddy event, the current would need to meander almost $700 \mathrm{~km}$ in 10 days. This requires a velocity of $0.8 \mathrm{~m} \mathrm{~s}^{-1}$ persisting for 10 days. Velocities observed by the mooring and satellite altimetry peak at $0.3 \mathrm{~m} \mathrm{~s}^{-1}$ in the vicinity of the current, so such a high velocity is unlikely.

An additional nine high salinity anomaly events did not show an obvious eddy hodograph signature but had turning velocity vectors associated with their salinity anomalies. This turning resembled that of the positively identified anticyclones, and they are likely to be anticyclones as well, despite their more irregular hodographs. These eddies are included in eddy counts and statistics as well as in the eddy identification in Fig. 2. Twenty-seven of the identified anticyclones exhibit two velocity maxima, meaning the mooring measurements occurred within $R_{\max }$, and 16 eddies showed expected alignment among all signals and were used in the estimate of $R_{\max }$. Anticyclones had core salinities and potential temperatures of $34.91-34.98$ and $4.48^{\circ}-5.34^{\circ} \mathrm{C}$, respectively. These values represent a typical salinity anomaly of 0.03 and temperature anomaly of $0.28^{\circ} \mathrm{C}$ from noneddy values. Figure 4 shows the results of the eddy property estimates from the mooring data from 2002 to 2009 . The mean anticyclone diameter was $12 \mathrm{~km}$. The estimate of $V_{\max }$ ranges from $0.04 \mathrm{~m} \mathrm{~s}^{-1}$ to $0.22 \mathrm{~m} \mathrm{~s}^{-1}$ (Fig. 4b), and has a mean of $0.10 \mathrm{~m} \mathrm{~s}^{-1}$. Figure $4 \mathrm{c}$ shows the translation vector $\mathbf{U}$ for each anticyclone with a core crossing. The mean translation speed is $0.026 \mathrm{~m} \mathrm{~s}^{-1}$, about one order of magnitude smaller than the eddy component of the velocity signal. Eddy translation appears to be most common toward the northeast. Although the CIS mooring was placed in the center of the lowest surface dynamic topography, some middepth recirculation was inferred by Lavender et al. (2000) at that location. Our eddy translations are consistent with that larger-scale middepth gyre circulation pattern.

The Rossby number Ro is defined as Ro $=\left|V_{\max }\right| \mid$ $\left(R_{\max } f\right)$ (see Hebert et al. 1990). There are a few choices for the horizontal scale and velocity maximum that can be used in the calculation of Ro; here, the variables $R_{\max }$ at $V_{\max }$ are used because they represent the dynamic variables associated with eddy velocities. The Rossby numbers of the mooring anticyclones ranged between 0.01 and 1 and had a mean value of 0.3 . These Rossby numbers suggest eddies with geostrophically dominated flow.

The total number of anticyclones observed each year is shown in Fig. 4d (including those whose core was not crossed). Counts represent eddy totals beginning each 

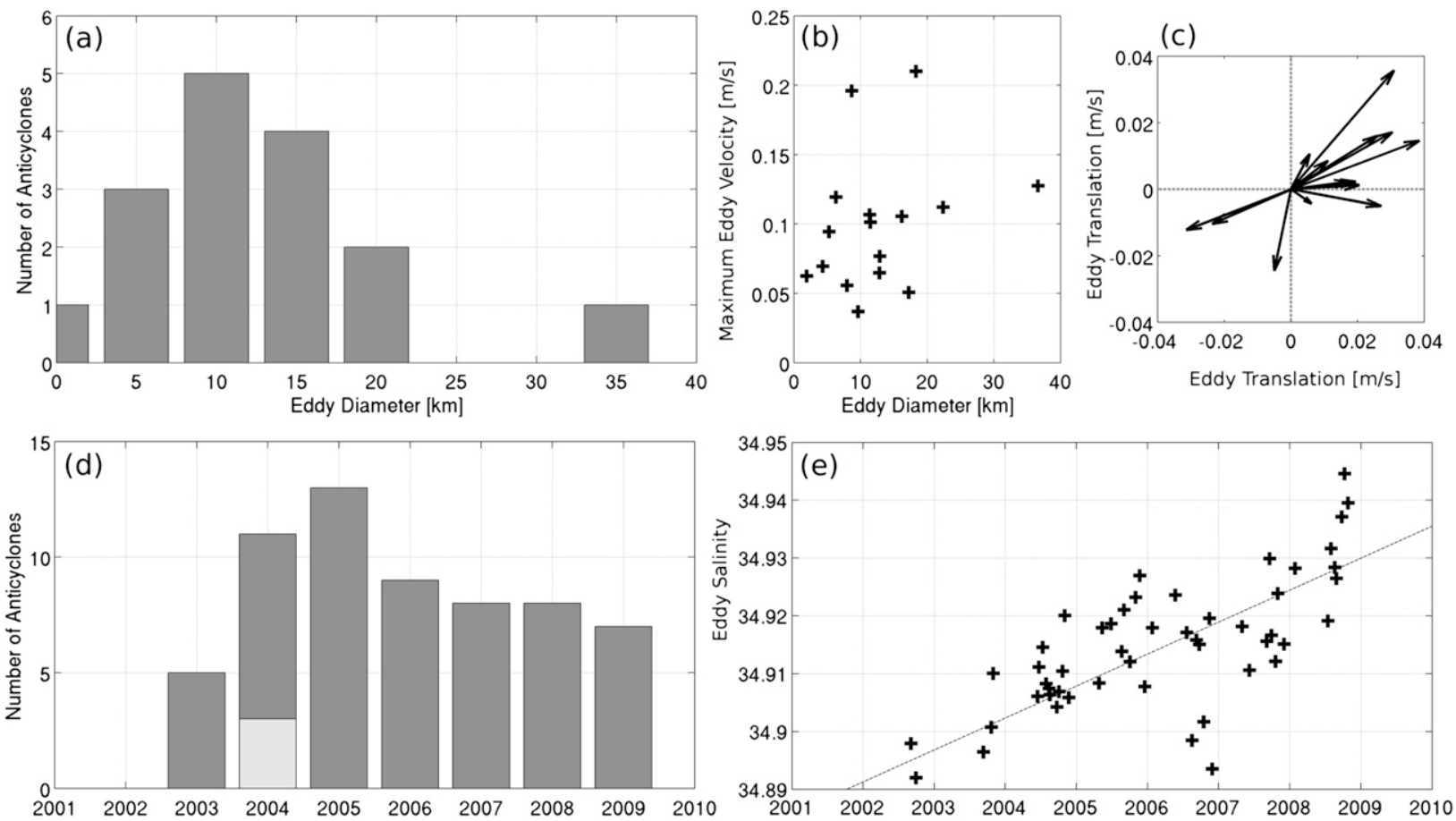

FIG. 4. Results from eddy census using the mooring algorithm. (a) Number of anticyclones found at a given diameter scale $2 R_{\text {max }}(\mathrm{km})$. (b) Maximum velocities $\left(\mathrm{m} \mathrm{s}^{-1}\right)$ encountered at each anticyclone plotted against diameter. (c) The translation vector for each anticyclone encounter. (d) Number of eddies each year, counted beginning in Junes of each year. The bar placed at year 2003 represents counts from June 2002 to June 2003, and so on. This count includes eddies whose cores were not observed as well as "likely" anticyclones (9 total) which had a typical salinity anomaly signature and turning velocities, but an atypical hodograph. Note that between June 2003 and 2004 , there was very little mooring data, resulting in the low eddy number shown in the light gray bar. We estimate the total number of eddies that would have been observed during this period if we had a full dataset by dividing the eddy count by the time fraction during which data are available that year. This estimated count is shown by the dark gray bar. (e) The surface to 1000-m mean eddy salinities plotted against date of occurrence. The black dotted line represents the fitted linear trend.

June. The counts for the period 2003/04 are extrapolated because of sampling gaps that year; we estimate the total number of eddies that would have been observed during this period if we had a full dataset by dividing the eddy count by the time fraction during which data are available that year. The number of anticyclones observed each year is not steady, and an almost threefold increase in eddy occurrences is observed from 2003 to 2005 followed by a period of lower counts. There is a salinifying trend of the eddy cores plotted in Fig. 4e. The observed trend in surface to $1000 \mathrm{~m}$ mean salinities of anticyclones is $5.7 \times 10^{-3} \mathrm{yr}^{-1}$, identical to the salinifying trend over the entire time series, described earlier. This suggests that the properties of eddies and noneddy water in the Irminger Basin are linked. These trends will be examined in detail in Part II.

\section{Anticyclones observed by a glider}

Two eddies, marked by yellow boxes on the property profiles in Figs. 5a and 5b, are encountered by the glider.
Each time the glider observes a feature with bowlshaped isopycnals and anticyclonically turning velocities. These anticyclones have a well-mixed core of salty $(>34.95)$ and warm $\left(>5.5^{\circ} \mathrm{C}\right)$ water between 200 and $700 \mathrm{~m}$. The core layer coincided with bowl-shaped isopycnals below $400 \mathrm{~m}$ and a doming of isopycnals above it. This type of structure resembles that of a mode water eddy (e.g., McGillicuddy et al. 2007) and is similar to the structure of some Labrador Sea ICAs and Meddies found in the North Atlantic basin (Richardson et al. 1989). Satellite altimetry in the region (Figs. 5c and 5d) shows an anticyclonic structure centered at approximately $59.8^{\circ} \mathrm{N}, 36.5^{\circ} \mathrm{W}$ that is crossed by the glider.

\section{a. Method}

Our goal here is to sort glider profiles in terms of distance from the eddy center, allowing us to estimate the size and show the property distributions of the eddy. As the glider follows its trajectory, we assume that the eddy is also moving with a depth-independent, constant translation $\mathbf{U}$, as we did in the mooring method. We 

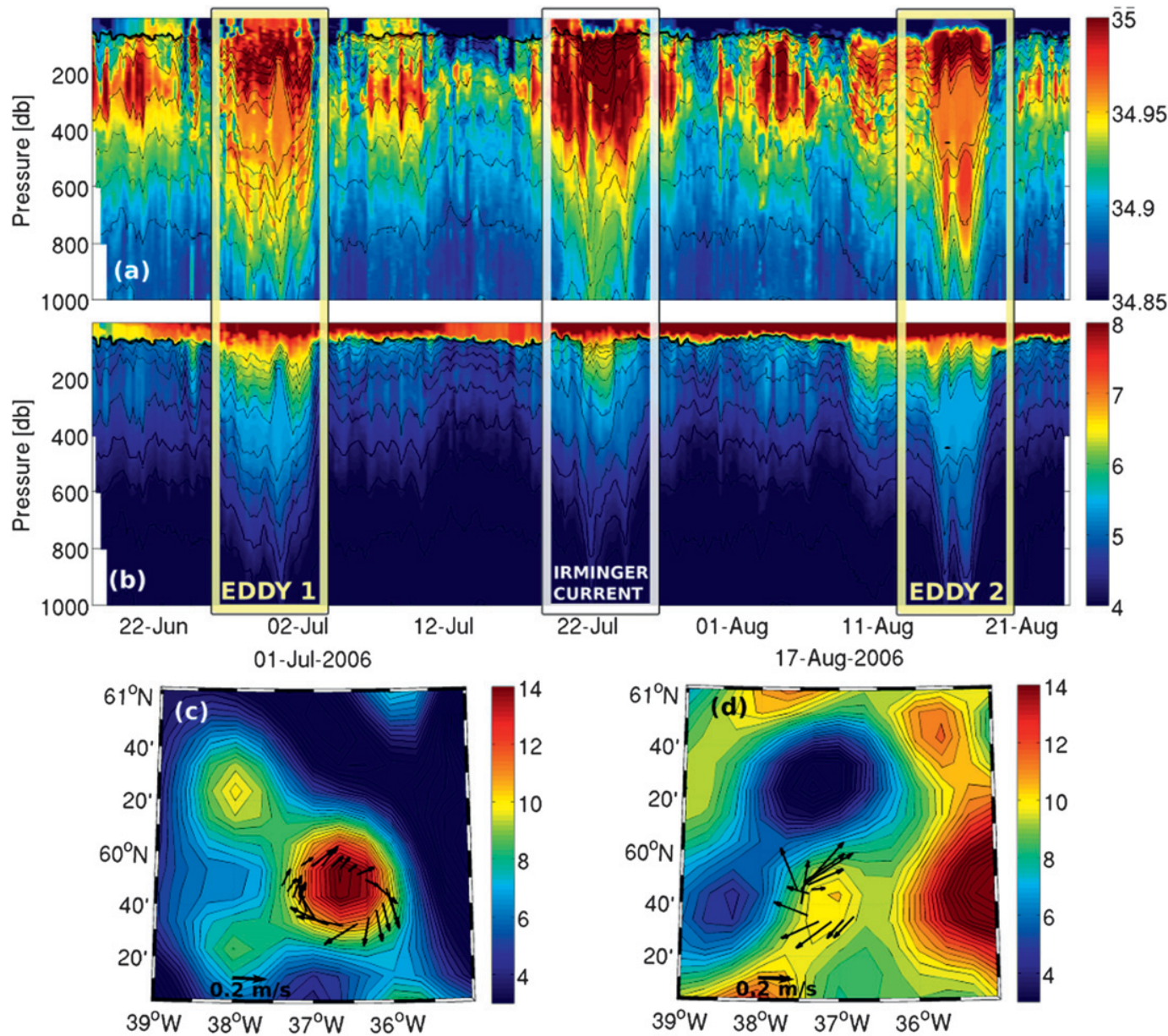

FIG. 5. Glider profiles. (a) Salinity in color with potential density contours in black $\left(0.02 \mathrm{~kg} \mathrm{~m}^{-3}\right.$ apart). (b) Potential temperature $\left({ }^{\circ} \mathrm{C}\right)$ in color with potential density contours in black $\left(0.02 \mathrm{~kg} \mathrm{~m}^{-3}\right.$ apart $)$. (left) Eddy 1 and (right) eddy 2 are highlighted in yellow, along with a crossing of the Irminger Current (in white). Between eddy 1, the Irminger Current, and eddy 2, patches of lenslike high salinity features are observed. The density of these features is similar to that of the Irminger Current, and they are likely to be subsurface filaments from the current and not an eddy feature. (c),(d) Depth-averaged current vectors from glider measurements and SLA $(\mathrm{cm})$ from satellite altimetry on a date near the eddy encounters.

want to position each glider dive relative to the translating eddy center. To do this, we move each glider dive back a distance $|\mathbf{U}| \Delta T$ in the direction $-\mathbf{U}$. Here, $\Delta T$ is the time elapsed from the first dive. This places each glider dive relative to the position of the eddy center at the time of the first dive. We find the $\mathbf{U}$ that minimizes the variance of the radial component of velocity after subtracting $\mathbf{U}$ from observed velocities. This assumes that the velocity signal (other than $\mathbf{U}$ ) is dominated by the azimuthal eddy velocity, and the radial component is small [see Martin et al. (2009) for an example of this method]. In this fit, the remaining unknown to be determined is the center location corresponding to the eddy at the first glider dive. After placing each dive relative to the eddy center, we can sort properties and view them with respect to distance from the center. The continuity of the data is an indication of successful sorting. This method gives information about eddy size and peak velocity, the quantities of interest analyzed also by the mooring method outlined earlier.

The treatment of the glider data presented here is significantly simpler than that for mooring data. We discuss here why we cannot use the glider method on the mooring data. If a glider flew in a straight line through an eddy, the resulting profiles would be no different from an eddy moving past a mooring. However, if an idealized eddy were transected in a straight line through its center, its velocity vectors would be everywhere perpendicular to this line, so the variance of the radial component of velocity is zero everywhere 

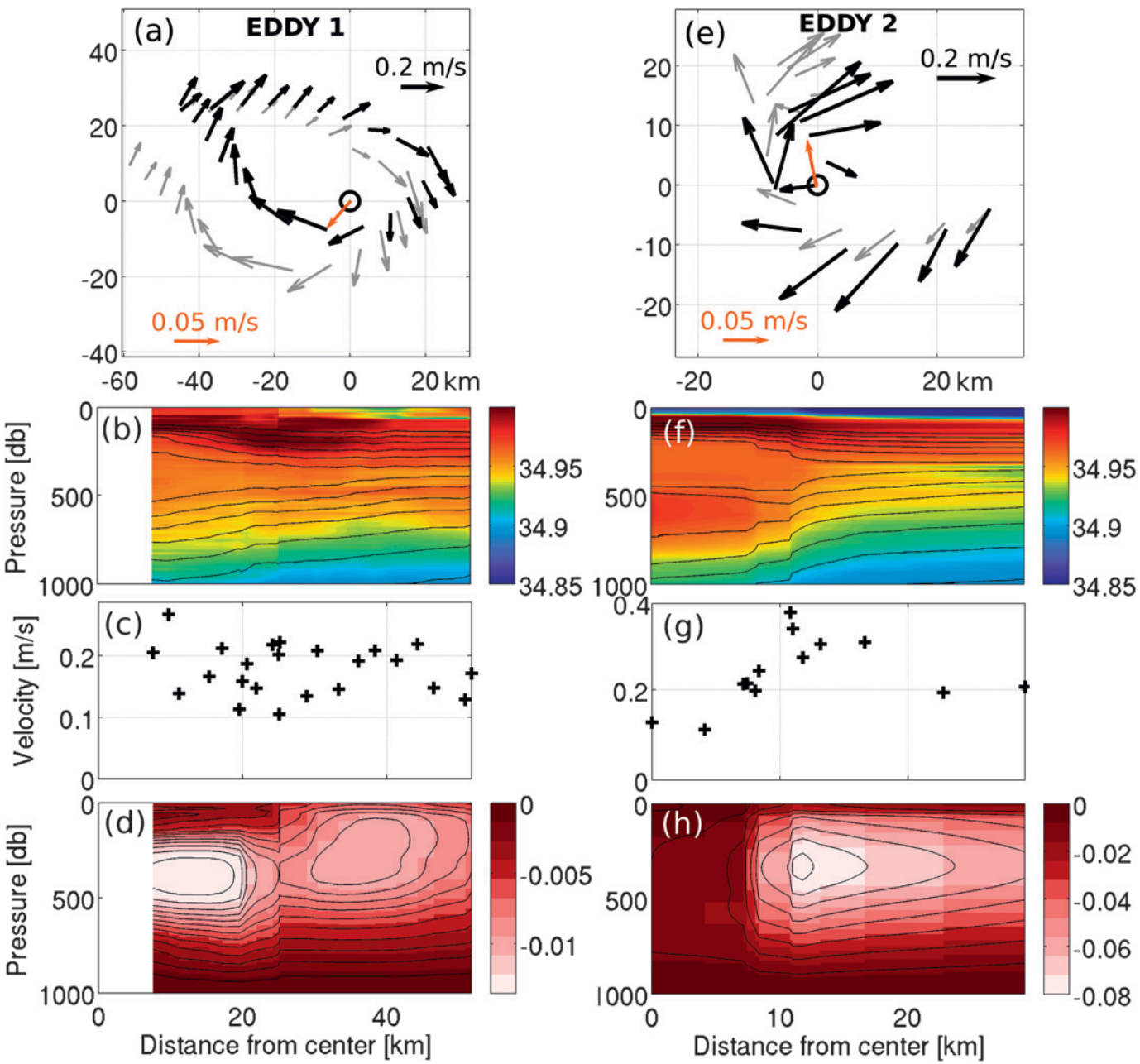

FIG. 6. Sorted glider profiles from (left) eddy 1 and (right) eddy 2. (a),(e) Depth-averaged velocity vectors before (gray) and after (black) applying the method described in the text. The vectors show velocity measurements with respect to the eddy center of the first dive. The scale for both the gray and black vectors is the black arrow. The orange vector represents the direction of the translation velocity obtained from the fit, and (bottom left) its scale is the orange arrow. The black arrows have the translation velocity removed. (b),(f) Color contours of salinity and line contours of potential density $\left(0.02 \mathrm{~kg} \mathrm{~m}^{-3}\right.$ contour spacing). (c),(g) Magnitude of the tangential component of the depth-averaged velocity $\left(\mathrm{m} \mathrm{s}^{-1}\right)$ after data method is applied. (d),(h) Geostrophic velocity ( $\mathrm{m} \mathrm{s}^{-1}$ ) referenced to $1000 \mathrm{~m}$, with negative values coming out of the page. Panels (b)-(d),(f)-(h) are plotted vs distance from the eddy center.

along the line. This creates an infinite number of solutions satisfying our minimization, and the fit does not converge. Thus, the closer the transect is through the center of the eddy, the more difficulty we have obtaining a converging solution. Ultimately, what is needed for the glider method to work is the turning of velocity vectors, which is easily achieved by the glider dataset because the glider did not move in a straight line. It is also achieved for straight transects far from the eddy center and outside of the core radius; however, in this situation one does not obtain information about the eddy radius, $R_{\max }$. Because of these limitations, the method outlined in section 3 was developed to work specifically for a mooring.

\section{b. Results}

Figure 6 shows the sorted properties from the two glider eddy encounters. The fit moved velocity measurements at each dive (gray arrows in Figs. 6a,b) in the direction of $\mathbf{-} \mathbf{U}$ to obtain the resulting eddy velocities plotted relative to the first eddy center location (black arrows in Figs. 6a,b). The translation vector $\mathbf{U}$ is shown as the orange arrow in both panels. The minimization resulted in translation speeds of 0.05 and $0.06 \mathrm{~m} \mathrm{~s}^{-1}$ for 
eddy 1 and eddy 2 , respectively. Both translation values are higher than those observed at the mooring, but because these eddies were observed to the east of the mooring, they may be embedded in a stronger circulation. Density contours (Figs. 6b,f) steepen closer to the eddy center. In both eddy 1 and eddy 2 , a salty $(>34.95)$, warm $\left(>5.5^{\circ} \mathrm{C}\right)$ homogeneous core extends from 200 - to $700-\mathrm{m}$ depth, having properties similar to the mooring anticyclones.

The magnitude of the azimuthal component of velocity (with $\mathbf{U}$ removed) is shown in Figs. 6c and 6g. For eddy 1 , velocities decrease slightly from the largest value of $0.28 \mathrm{~m} \mathrm{~s}^{-1}$ observed at about $10 \mathrm{~km}$ distance. This implies that the glider did not enter the eddy core, so the eddy $V_{\max }$ was not observed. Following our eddy model, $R_{\max }$ for eddy 1 must be less than or equal to $10 \mathrm{~km}$. The glider did appear to enter the core of eddy 2 , shown by the peak in velocity of $0.39 \mathrm{~m} \mathrm{~s}^{-1}$ (Fig. $6 \mathrm{~g}$ ), suggesting an $R_{\max }$ at about $10 \mathrm{~km}$. The $R_{\max }$ values for eddy 1 and eddy 2 fall within the range of eddy sizes observed by the mooring. However, in both cases, eddy velocities exceeded those observed by the CIS mooring. The glider velocities are likely biased high because they have not had a low-pass filter applied to remove signals from tides, inertial currents, and other noneddy phenomena, as was done with the mooring data. Since it is not possible to apply the same kind of filter to the glider data, it will retain the more extreme values. Geostrophic velocities calculated from the density profiles and referenced to $1000 \mathrm{~m}$ and are shown in Figs. 6d and 6h. Both eddies have a subsurface maximum centered at about $400 \mathrm{~m}$. The maximum geostrophic velocity of eddy 2 occurs at $R_{\max }$. It appears that the maximum in eddy 1 increases toward shorter distances, and may also be at maximum at its $R_{\max }$. In the case of eddy 1 , the geostrophic velocity structure beyond about $25 \mathrm{~km}$ is likely not due to the eddy. Geostrophic velocities in eddy 1 are substantially smaller than those of eddy 2 , related to less steep isopycnals in the former. This is expected if the observations in eddy 1 are further from the center. Compared to maximum velocities observed at the mooring site, the maximum geostrophic velocities observed by the glider fall in the same range. The Rossby number for eddy 2 is 0.26 (but we cannot compute this for eddy 1 since we did not observe its $V_{\max }$ ). This is well within the range of Rossby numbers from mooring anticyclones, and again suggests a vortex dominated by geostrophy.

\section{Basin-wide anticyclone activity}

To determine whether the anticyclones observed by the mooring and glider are representative of anticyclones found throughout the Irminger Sea, we use Argo float profiles (shown with gray circles in Fig. 7a) to find high salinity anomalies throughout the Irminger Sea and determine whether they are anticyclones similar to those observed by the mooring and glider. We do this in two ways: using satellite altimetry and salinity thresholds. The altimetry method finds the sea level anomaly (SLA) corresponding to each float profile. Float profiles taken at locations having $>8 \mathrm{~cm}$ SLA were considered anticyclones, and each such SLA anomaly was checked for a closed contour of SLA, ensuring that meanders or filaments were not included. This method is expected to underestimate eddy numbers because of the resolution of altimetry, but positively identified profiles are likely to be eddies.

The salinity threshold method is based on our previous observations of anticyclones having anomalously high salinities. This method uses a determined salinity threshold beyond which profiles are considered anticyclones. Transects across the Irminger Sea (e.g., Våge et al. 2011) show a gradient in salinity with low values to the west, so choosing one threshold to apply across all eddies in the Irminger Sea would be inappropriate. Instead, thresholds are defined as a local mean salinity plus one standard deviation; these values are calculated from a combination of float profiles and climatology from the World Ocean Atlas 2009 (WOA09) product. This method and the WOA09 dataset are described in detail in the appendix. Salinity thresholds used in this method ranged from 34.92 to 34.99 , spanning similar threshold values used in the CIS mooring analysis.

We first examine the properties of eddies obtained by the altimetry method. The salinity and temperature at $260 \mathrm{~m}$ (a typical anticyclone core depth) of the float anticyclones determined by this method are plotted as gray circles in Fig. 7b, along with the mean properties from the mooring eddies (red stars). Care was taken to only examine profiles located within the blue ellipse shown in Fig. 7a; this is to avoid contaminating the data with profiles from the boundary current. The float profiles all exhibited high salinity (often $>35.0$ ), confirming the presence of salty anticyclones as seen by the mooring and glider throughout the Irminger Basin. The highest anticyclone salinities in Fig. 7b exceed mooring anticyclone core salinities; these high values were found in the most northeast region of the Irminger Basin (see Fig. 7a). Since the altimetry method likely misses some floats within anticyclones, for a more complete float eddy census, the salinity threshold method is used. A total of 130 anticyclones from 2002 to 2009 were found by the salinity threshold method, and are circled in black in Fig. 7a. 

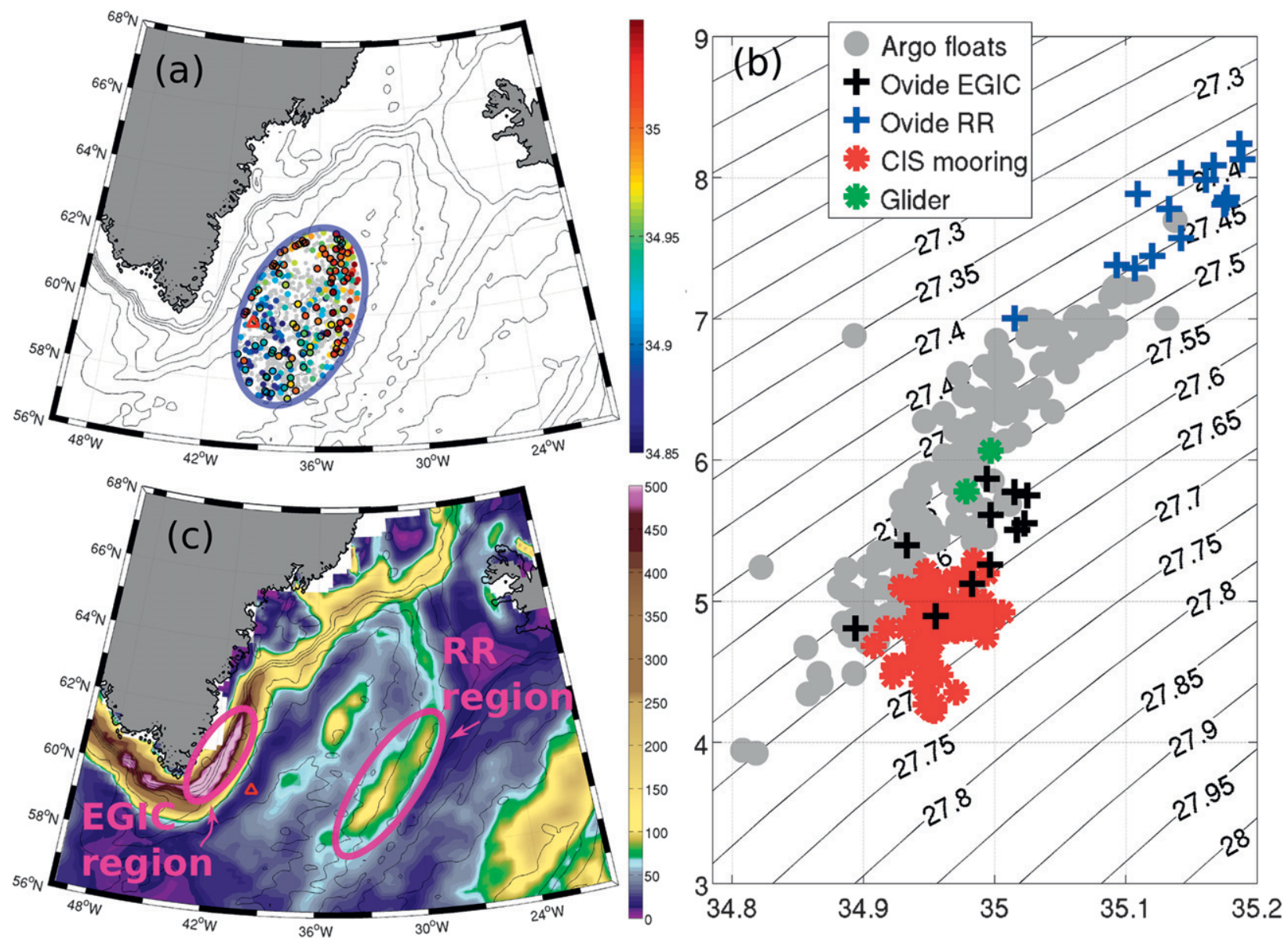

FIG. 7. (a). Argo float data from 2002 to 2006, showing salinities at 260-m depth. Floats within the ellipse shape are considered for eddy search. Gray filled circles represent all float data, and floats shown in color represent uncorrelated measurements. Circled in black are profiles identified as eddies using the salinity theshold method. Colors represent the salinity at $260 \mathrm{~m}$. The red triangle marks the CIS mooring location. (b) Temperature-salinity plot of measurements (at 260-m depth) of float profiles within anticyclones determined by the altimetry method (gray filled circles). Anticyclone properties at 260-m depth from the mooring and the glider are represented with red and green asterisks, respectively. Ovide transects through the RR region (blue crosses) and EGIC (black crosses) are also plotted at $260 \mathrm{~m}$. (c) Mean EKE $\left(\mathrm{cm}^{2} \mathrm{~s}^{-2}\right)$ calculated from satellite altimetry-derived geostrophic velocity anomaly averaged over 2000-09. Black lines are contours of topography (500 m apart). The red triangle marks the CIS mooring location. Two formation regions are circled: RR region and EGIC region.

\section{Eddy origin}

We now investigate possible origins for the anticyclones observed. The only high salinity sources in the Irminger Sea are the Irminger Current and the EGIC, an extension of the Irminger Current. To examine the basin-wide hotspots of eddy activity, we will first examine EKE derived from satellite altimetry, shown in Fig. 7c. EKE is defined as

$$
\mathrm{EKE}=\frac{1}{2}\left(u^{\prime 2}+v^{\prime 2}\right),
$$

where $u$ and $v$ denote the zonal and meridional geostrophic velocities, respectively, and the prime denotes an anomaly with respect to the mean state. Here, we use the gridded AVISO geostrophic velocity anomaly product which is referenced to the 1992-2005 mean sea surface. We observe three regions of elevated EKE in Fig. 7c: just west of the Reykjanes Ridge, along the EGIC on the east coast of Greenland, and in the center of the Irminger Basin. This last region cannot be a formation site because there is no source of high salinity there and is more likely a site of eddy "congregation," possibly because of the deeper water there (see Huppert and Bryan 1976; Bretherton and Haidvogel 1976; Carnevale et al. 1991; Cenedese and Linden 1999). We will refer to the region of the Irminger Current west of the Reykjanes Ridge as the "RR" region, our first potential eddy formation site. A second potential site of eddy formation is found along the EGIC just south of 

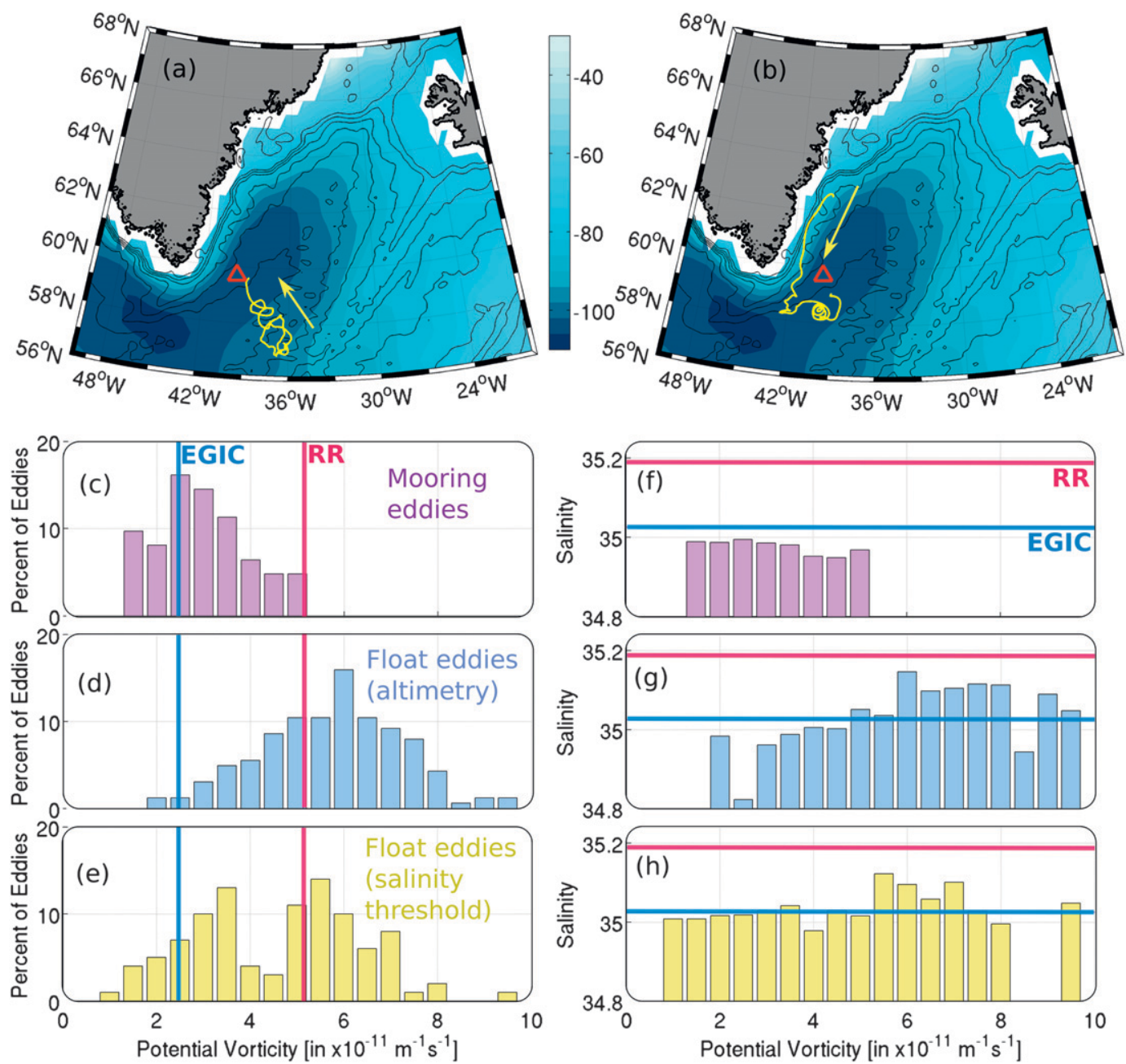

FIG. 8. Drifter tracks showing an instance of an eddy originating from the (a) RR region and the (b) EGIC region. The blue color contours represent the mean dynamic topography $(\mathrm{cm})$ displayed and described in Fig. 1. Black contours show the bottom topography in 500-m increments. Yellow arrows indicate the direction of movement of the drifter. (c) Histogram of 200-700-m-averaged PV calculated from mooring anticyclones. (d) As in (c), but for Argo float anticyclones determined by the altimetry method. (e) As in (c), but for Argo float anticyclones determined by the salinity threshold method. In (c)-(e), the blue line indicates the mean PV at the EGIC region, and the pink line, the mean PV at the RR region (determined from Ovide ship measurements). (f)-(h) Maximum observed salinity corresponding to each PV bin for anticyclones shown in (c)-(e), respectively. The maximum salinities observed at the EGIC and RR regions are shown with the blue and pink lines, respectively.

Cape Farewell, where the EGIC retroflects and where some eddy variability has been observed previously (see Holliday et al. 2007; Daniault et al. 2011); this site will be referred to as "EGIC." Both possible formation sites are circled in Fig. 7c. To illustrate the existence of Irminger Sea eddies coming from both regions, Figs. 8a and 8 b show two drifter tracks, one passing through each site. Figure 8 a shows a drifter trapped in an eddy at the $\mathrm{RR}$ region, and then moving to the gyre center. The drifter in Fig. 8 b follows the EGIC and breaks away near Cape Farewell, then moves toward the central gyre in a spiral, again trapped in an eddy.
Now we compare observed eddy core properties with properties from the two proposed formation sites. The Ovide cruises (whose cruise path is included in Fig. 1) crossed both the EGIC and RR regions in the summers of 2002, 2004, and 2006. Their salinity and temperature at $260 \mathrm{~m}$ (a typical eddy core depth) is shown in Fig. 7b. There is an obvious salinity change in the Irminger Current, moving from higher salinities $(>35.1)$ at the $\mathrm{RR}$ region to 34.89-35.02 at the EGIC region. The salinities from the EGIC and the mooring eddy cores are similar. The Argo eddies have a much broader salinity range, with salinities exceeding those observed at the 
EGIC. These saltier eddies must be formed upstream of the EGIC, presumably at the RR region. The eddies found at the mooring site can have two origins: they can either be formed at the EGIC, or be long-lived eddies formed upstream that have lost some of their high salinity anomaly to surrounding waters as they propagated to the mooring site.

To determine which possibility is more likely, we assume that the anticyclones preserve the large-scale potential vorticity (PV), or stratification, from their formation site. We calculate PV for the EGIC and RR regions as well as for mooring and float eddies. The quantity PV describing the stratification (and ignoring the relative vorticity term) is defined, following Talley (1988), as

$$
\mathrm{PV}=\frac{f}{\rho_{o}} \frac{\partial \rho}{\partial z},
$$

where $z$ is the depth. Because the salinity cores are found between 200 and $700 \mathrm{~m}$, we calculate the average $\mathrm{PV}$ in this layer and all subsequent mentions of PV refer to 200-700-m layer averaged PV. We assume the quantity in (6) is conserved until the period of winter forcing (see section 7 for discussion of this), since we do not observe eddies which have survived a winter. The mean PV for all Ovide stations at the EGIC and RR regions, shown by the blue and red lines in Figs. $8 \mathrm{c}-\mathrm{e}$, is $2.4 \times 10^{-11} \mathrm{~m}^{-1} \mathrm{~s}^{-1}$ and $5.1 \times 10^{-11} \mathrm{~m}^{-1} \mathrm{~s}^{-1}$, respectively. Both regions have a standard deviation of $0.5 \times 10^{-11} \mathrm{~m}^{-1} \mathrm{~s}^{-1}$, meaning the PV values at the two sites are statistically distinct. The higher PV at the RR is explained by the higher stratification there compared to the EGIC (see Fig. 8 of Våge et al. 2011). At the RR, the Irminger Current's tilted isopycnals begin flattening around $500 \mathrm{~m}$, contributing to the increase in stratification and higher PV. At the EGIC, the current reaches the bottom of the basin and isopycnals do not flatten, resulting in a lower stratification and lower PV.

The histogram of PV values obtained from mooring and float anticyclones (determined by both the altimetry and salinity threshold methods mentioned earlier) are shown in the lower panels of Fig. 8. The count distribution of mooring eddy PV values (Fig. 8c) is centered around the EGIC value (almost $60 \%$ of the eddies have a PV within two standard deviations of the EGIC PV) with only a few values reaching the RR value. This suggests that mooring anticyclones are mainly formed from the EGIC region, a result supported by the preference for eddy translation to the northeast found by mooring (Fig. 4c). Float anticyclones obtained by the altimetry method (Fig. 8d) show a clear preference for RR PV values, whereas the salinity threshold method (Fig. 8e) produces a distribution with two peaks, one near the EGIC value, and the other at the RR value. It appears that eddies with EGIC properties are missed when determining float anticyclones from satellite. Interestingly, if we examine the tracked eddy paths produced by the Chelton algorithm, anticyclones with lifetimes greater than 16 weeks appear to be first detected exclusively over the RR region. We conclude that the satellite-based eddy detection must miss EGIC eddies because they are smaller than eddies formed at the RR region and could not be detected.

The maximum salinities at 260-m depth corresponding to each PV bin (Figs. 8f-h) show all eddies detected at the CIS mooring having salinities below the maximum EGIC salinity. As for float anticyclones, maximum salinities in the eddies exceed the maximum EGIC salinity in the higher PV range. These eddies, again, must be formed upstream of the EGIC. These results suggest that both the EGIC and RR regions are formation sites for the anticyclones, and these anticyclones are found throughout the Irminger Basin but have different sizes. The larger eddies observed by the floats are not encountered at the mooring.

\section{Comparison to other North Atlantic eddies}

This section describes observed properties of eddies found in the Labrador Sea and the Norwegian Sea and compares them to our Irminger Sea observations.

\section{a. Labrador Sea eddies}

Three types of eddies in the Labrador Sea have been observed: ICAs, Irminger Current cyclones, and convectively formed anticyclones. The most notable contributor to the heat and salt budget in the Labrador Sea are the ICAs. They play an important role in the advection of heat into the central Labrador Sea via their thick subsurface layer of warm Irminger Current water, and contribute $25 \%$ to $100 \%$ of the heat needed to balance the surface heat loss (Rykova et al. 2009; Hátún et al. 2007; Katsman et al. 2004; L03). ICAs are formed off the west coast of Greenland where the topographic slope changes (Eden and Böning 2002; Katsman et al. 2004; Bracco et al. 2008) and have a large sea surface height signal and elevated EKE (Prater 2002; L03; Lavender et al. 2005). Eddy numbers peak in winter (December to March), coinciding with a peak in the sea surface height variance (Prater 2002) and EKE (L03). Rykova et al. (2009) suggest that the ability for ICAs to maintain their structure through winters depends on the amount of surface forcing.

The published typical properties of ICAs in the Labrador Sea are summarized in Table 2. Observed core temperatures include $4.9^{\circ} \mathrm{C}$ (Prater 2002), $3^{\circ}-4.15^{\circ} \mathrm{C}$ 
TABLE 2. Summary of properties of anticyclones found in various basins in the North Atlantic. Columns are as follows: Diameter $D$ calculated from $R_{\max }$, diameter $D$ (Anom.) estimated by the salinity or temperature anomaly (and estimated as $4 R_{\max }$ for our mooring and glider eddies), temperature (Temp), salinity (Sal), maximum observed velocity $V_{\max }$, and Rossby number. The diameter ranges for eddies observed at the mooring are reported as one standard deviation about the mean observed eddy diameter.

\begin{tabular}{lcccccc}
\hline \hline & $D(\mathrm{~km})$ & $D($ Anom.) $(\mathrm{km})$ & Temp $\left({ }^{\circ} \mathrm{C}\right)$ & Sal & $V_{\max }\left(\mathrm{cm} \mathrm{s}^{-1}\right)$ & Rossby \\
\hline Labrador Sea & $10-70$ & $25-65$ & $3-4.9$ & $34.83-34.91$ & $20-80$ & $0.03-0.3$ \\
Lofoten Basin & & $50-60$ & $3.5-7$ & $>35$ & $13-40$ & $0.2-0.5$ \\
Irminger Sea (mooring) & $4-21$ & $8-42$ & $4.2-5.3$ & $34.97-35.01$ & $3-21$ & $0.01-1(\mathrm{mean} 0.3)$ \\
Irminger Sea (glider) & 20 & 40 & 5.5 & $34.91-35.01$ & $30-36$ & 0.26 \\
Irminger Sea (Argo) & & & $3.6-7.7$ & $34.8-35.15$ & & \\
\hline
\end{tabular}

(L03), $4.6^{\circ}-5.2^{\circ} \mathrm{C}$ (Hátún et al. 2007), and $3.2^{\circ}-4.9^{\circ} \mathrm{C}$ (Rykova et al. 2009). Core salinities include 34.85 (L03), 34.9 (Hátún et al. 2007), and 34.83-34.91 (Rykova et al. 2009). Approximate diameter ranges are 50 (Prater 2002), 30-60, (L03), and 60-70 km (Hátún et al. 2007). All ICAs were anticyclonic with positive sea surface height anomalies and bowl-shaped isopycnals, and had surface or near-surface intensified azimuthal velocities of 20-40 (Prater 2002), 30-80 (L03), and 50-70 $\mathrm{cm} \mathrm{s}^{-1}$ (Hátún et al. 2007). These values yield Rossby numbers ranging between 0.03 and 0.3 . Although the baroclinic nature of the ICAs is evident from the shape of the isopycnals and sheared velocity profiles, significant velocities within the ICA cores were observed even at depths exceeding $2000 \mathrm{~m}$ (L03). This suggests that both barotropic and baroclinic components contribute to the velocity field within an ICA.

\section{b. Lofoten Basin eddies}

A conspicuous region of high EKE in the Nordic seas exists in the Lofoten Basin (Poulain et al. 1996; Köhl 2007; Rossby et al. 2009b). The eddies with an important influence on the basin's properties are warm-core anticyclones. The anticyclones form near the coast of Norway where there is a rapid slope change (Rossby et al. $2009 \mathrm{~b}$ ), and then drift west and eventually coalesce with other anticyclones in the center of the basin (Köhl 2007). These anticyclones contain enough heat required to maintain the annually averaged heat loss in the Lofoten Basin (Rossby et al. 2009a), and serve to maintain the deep pycnocline in the center of the basin (Nilsen and Falck 2006; Köhl 2007; Rossby et al. 2009a).

A few shipboard and float measurements have been published on the anticylones, and these are summarized in Table 2. Core temperatures ranged from $3.5^{\circ}-4^{\circ} \mathrm{C}$ (Köhl 2007) to $6^{\circ}-7^{\circ} \mathrm{C}$ (Rossby et al. 2009a), and core salinities greater than 35 were observed (Köhl 2007). The maximum anticyclone diameter observed was about 50-60 km (Köhl 2007; Gascard and Mork 2008). Azimuthal velocities ranged from 13-26 (Gascard and Mork 2008) to $30-40 \mathrm{~cm} \mathrm{~s}^{-1}$ (Köhl 2007). These numbers yield Rossby numbers between 0.2 and 0.5 .

\section{c. Comparison to Irminger Sea anticyclones}

Individual characteristics of anticyclones from each basin spanned a broad range. The size of anticyclones at the CIS mooring is substantially smaller than the $75-\mathrm{km}$ eddy reported by Krauss (1995), but is in the range of anticyclone sizes observed in the Labrador Sea and Lofoten Basins. It should be noted that often, as in the Krauss (1995) study, eddy sizes are determined by the extent to which salinity or temperature is anomalous, and not by our definition of the core radius where maximum velocities are observed. Our observations show that the extent of the salinity (and temperature) anomaly can exceed the core radius by a factor of 2 or more at times, so our reported eddy sizes are by definition smaller than those observed by other studies. To make this difference clear, the eddy diameters reported in Table 2 are separated into diameters calculated from $R_{\max }$ and from property anomalies (estimated as $4 R_{\max }$ for our mooring and glider eddies). Maximum observed azimuthal velocities in our eddies were in the low range of velocities found in the other two basins. All anticyclones had low $(\ll 1)$ Rossby numbers, signifying dynamics dominated by geostrophic balance. Most ICAs in the Labrador Sea had surface or near-surface velocity maxima, whereas the Lofoten and Irminger anticyclones had more subsurface intensified velocity structures. Anticyclones in the Labrador Sea experience maximum numbers in winter months; the opposite appears to be true for the Irminger Sea anticyclones. Figure 2 shows anticyclone occurrences mainly in the summer months. During winter months, mixing down to at least $400 \mathrm{~m}$ is observed, and any observed remnants of high salinity anomalies do not have associated turning velocities that would indicate a coherent vortex. This suggests that at the mooring site, anticyclones may experience strong enough surface forcing to be destroyed during winter.

Despite the eddies' differences, we can generalize: lenslike anticyclones are observed in all three highlatitude North Atlantic basins that we have examined. Although individual properties vary, their broad characteristics are the same. All anticyclones form from 
a boundary current over steep topography, suggesting that baroclinic instabilities produced from topography (see Wolfe and Cenedese 2006) can be a ubiquitous formation mechanism for lenslike anticyclones in the subpolar North Atlantic.

In both the Labrador Sea and Lofoten Basins, anticyclonic eddies play an important role in balancing winter heat loss as a result of their anomalous warm cores. This is likely also the case for Irminger Sea, where warm anticyclones have the potential to contribute to the heat balance of the Irminger Sea. In the Labrador Sea, the anomalously fresh anticyclones balance the freshwater budget (Hátún et al. 2007); analogously, our Irminger Sea anticyclones have the potential to contribute to the freshwater budget resulting from their anomalous salinity signature.

\section{Discussion}

At the CIS mooring, we have observed warm, salty anticyclones that are found throughout the Irminger Basin. Eddies observed at the mooring are of EGIC origin, and eddies originating from the RR region do not typically reach the mooring location. The benefit of the mooring and glider observations is the ability to obtain a detailed, quantitative representation of eddy structure and frequencies which cannot be done with existing datasets spanning large spatial domains.

Although our analysis suggests two separate formation regions for the Irminger Sea anticyclones, satellite altimetry appears to identify only one of them. As mentioned, the gridded satellite altimetry product dampens eddy signals smaller than $40 \mathrm{~km}$ (Chelton et al. 2011). The mooring anticyclones had a mean $R_{\max }$ of $6 \mathrm{~km}$; since this corresponds to an eddy size of $24 \mathrm{~km}$, most of the altimetry signal of these eddies will be dampened. This suggests that the eddies detected by satellite altimetry and which appear to form at the RR region are larger than those observed at the mooring site. Because we do not observe the larger eddies at the mooring, we do not have sufficient data to analyze them.

The horizontal scales of the eddies observed in the CIS appear to scale with the first baroclinic Rossby radius of deformation $R_{1}$ (Emery et al. 1984; Chelton et al. 1998). We calculate this quantity following Emery et al. (1984) and compare it to our observed eddy scales. As in Emery et al. (1984), values of the squared buoyancy frequency are linearly extrapolated from the deepest measurement to zero at the sea floor. We calculate $R_{1}$ using our available datasets. The mean $R_{1}$ obtained from the mooring, glider, Argo floats, and Ovide transects is 5.6, 7.0, 7.5, and $10.7 \mathrm{~km}$, respectively. The most unstable wavelength $L_{1}$ of the baroclinic instability process is given by $L_{1}=2 \pi R_{1}$ (Emery et al. 1984; Stammer and Böning 1992). The diameter of eddies resulting from this instability is expected to be $L_{1} / 2$. Our $R_{1}$ values predict eddies to have diameters of $17.7,22.0,23.7$, and $33.6 \mathrm{~km}$ from the data sources listed previously. This expected eddy diameter should be compared to our observations of the size of the salinity or temperature anomaly of $4 R_{\max }$ from our analyses (Table 2 ). Our observed anticyclone sizes fall within the range of diameters predicted from the first baroclinic Rossby radius.

This study has focused on anticyclonic eddies with warm and salty core anomalies found in the Irminger Basin. We have concentrated on these eddies because of their analogous traits to anticyclones in the Labrador and Norwegian Seas, and their potential for influencing budgets of the Irminger Sea. These anticyclones appear to be a general feature of subpolar North Atlantic basins. Further work must be done to determine the impact and fate of the anticyclones in the Irminger Sea. As mentioned, the eddies at the CIS mooring show interannual variability in occurrence, and their core salinity shows an increase over the time series. We expect this to be an important source of salt for the Irminger Sea, and a quantitative analysis using the eddy statistics from this study will be done in Part II.

Acknowledgments. We thank the teams of LPO/ IFREMER, LOCEAN/CNRS, PO/IFM-GEOMAR, and PORD/SIO for performing the 2006 Spray glider mission, and specifically Thierry Terre (LPO) and Jeff Sherman (SIO) for making the mission possible. Gratitude goes to the reviewers and Sarah Gille for valuable advice on the manuscript. This work benefitted from discussions with George Carnevale and William Young. Funding for the CIS mooring was provided by the European Ocean Observatory Network (EuroSITES) and the glider was operated with MERSEA support. Altimeter data was provided via the AVISO website (http://www.aviso.oceanobs.com). Argo data was provided by the USGADAE Project website (http://www. usgodae.org). Drifter data was provided by the NOAA AOML Global Drifter Program website (http://www. aoml.noaa.gov/phod/dac/index.php).

\section{APPENDIX}

\section{Determining Argo Float Eddies Using Local Threshold}

We want to determine if an Argo float profile is within an anticyclone by applying a salinity threshold, and then obtain a basin-wide eddy census. First, profiles taken in 
independent eddies must be found to eliminate bias from floats trapped in float eddies. The average (quasiLagrangian) decorrelation scale for temperature and salinity at $260 \mathrm{~m}$ (a typical eddy core depth) estimated from over 50 floats that entered the Irminger Sea is 50 days. This means that on average, float profiles (from the same float) greater than 50 days apart will be uncorrelated and not be part of the same feature.

We want to define a salinity threshold beyond which a float profile is in an anticyclone. A salinity gradient is observed across the Irminger Sea from previous observations (see Våge et al. 2011), so applying one threshold to all floats would be inappropriate. Instead, we need thresholds dependent on a given region. We obtain the background salinity field from the WOA09 product. WOAO9 is a set of objectively analyzed ( $1^{\circ}$ grid) climatological fields of in situ measurements at standard depth levels for annual, seasonal, and monthly compositing periods for the World Ocean. Here, we have used the mean salinity product, whose details are found in Antonov et al. (2010). The WOA09 mean salinity field at $260 \mathrm{~m}$, as expected, shows higher salinities in the northeast region of the Irminger Sea and lower salinities in the southwest. We compare the WOA09 salinity in the Irminger Sea with mean uncorrelated Argo float salinities averaged over $100 \mathrm{~km}$ by $100 \mathrm{~km}$ bins over the basin.

First, we compare statistics for an area $100 \mathrm{~km}$ around the CIS mooring, assuming that the mooring statistics are representative of this region. At the WOA09 nearest grid point, the mean salinity at $260 \mathrm{~m}$ is 0.02 lower than the mean noneddy salinity at the mooring. This is expected since we know the mooring sampled during a time of increased salinities (Sarafanov et al. 2007) compared to climatology. The Argo float mean at $260 \mathrm{~m}$ in this region is 0.02 higher than the mooring noneddy mean; this is because of the floats sampling both eddies and noneddy water. The salinity threshold is defined as the mean plus one standard deviation (STD). The STD used for the WOA threshold is the mooring STD, which represents the variability in salinities in the region. The STDs used for the WOA and Argo floats are 0.02 and 0.04 . These values resulted in a WOA threshold of 34.94 , and an Argo float threshold of 34.96. Because the WOA threshold is likely biased low, and the Argo float threshold is biased high, we take the mean of the two to be our threshold to find eddies.

Using this threshold, $22 \%$ of uncorrelated float profiles within $100 \mathrm{~km}$ of the mooring are eddies. We assume that the percent of time the mooring time series is occupied by an eddy is equivalent to the percent of float profiles that happen to sample in an eddy. This essentially means that the probabilities of picking a point within an eddy are the same if one randomly picks a point in time or a point in space. The mooring shows about $18 \%$ of the time series is occupied by high salinity associated with anticyclones. This is similar to the percent of float profiles picked by the threshold method in this region, suggesting that the threshold method is valid. We extend this method to the entire basin by making $100 \mathrm{~km}$ by $100 \mathrm{~km}$ bins and picking float eddies from local salinity thresholds at $260 \mathrm{~m}$ in each bin.

\section{REFERENCES}

Antonov, J. I., D. Seidov, T. P. Boyer, R. A. Locarnini, A. V. Mishonov, and H. E. Garcia, 2010: Salinity. Vol. 2, World Ocean Atlas 2009, NOAA Atlas NESDIS 69, 184 pp.

Armi, L., D. Hebert, N. Oakey, J. Price, P. Richardson, H. Rossby, and B. Ruddick, 1989: Two years in the life of a Mediterranean salt lens. J. Phys. Oceanogr., 19, 354-370.

Bracco, A., J. Pedlosky, and R. Pickart, 2008: Eddy formation near the west coast of Greenland. J. Phys. Oceanogr., 38, 1992-2002.

Bretherton, F., and D. Haidvogel, 1976: Two-dimensional turbulence above topography. J. Fluid Mech., 78, 129-154.

Bruce, J., 1995: Eddies southwest of the Denmark Strait. Deep-Sea Res. I, 42, 13-17.

Carnevale, G., R. Kloosterziel, and G. Van Heijst, 1991: Propagation of barotropic vortices over topography in a rotating tank. J. Fluid Mech., 233, 119-139.

Cenedese, C., and P. Linden, 1999: Cyclone and anticyclone formation in a rotating stratified fluid over a sloping bottom. J. Fluid Mech., 381, 199-223.

Chelton, D., R. DeSzoeke, M. Schlax, K. El Naggar, and N. Siwertz, 1998: Geographical variability of the first baroclinic Rossby radius of deformation. J. Phys. Oceanogr., 28, 433-460.

_- M. Schlax, R. Samelson, and R. de Szoeke, 2007: Global observations of large oceanic eddies. Geophys. Res. Lett., 34, L15606, doi:10.1029/2007GL030812.

,-- , and -2011 : Global observations of nonlinear mesoscale eddies. Prog. Oceanogr., 91, 167-216.

Daniault, N., P. Lherminier, and H. Mercier, 2011: Circulation and transport at the southeast tip of Greenland. J. Phys. Oceanogr., 41, 437-457.

De Jong, F., 2010: Hydrographic variability of the Irminger Sea. Ph. D. thesis, University of Utrecht, $208 \mathrm{pp}$.

De Jong, M., H. van Aken, K. Våge, and R. Pickart, 2012: Convective mixing in the central Irminger Sea: 2002-2010. DeepSea Res. I, 63, 36-51.

Ducet, N., P. Le Traon, and G. Reverdin, 2000: Global high-resolution mapping of ocean circulation from TOPEX/Poseidon and ERS-1 and -2. J. Geophys. Res., 105 (C8), 19 477-19 498.

Eden, C., and C. Böning, 2002: Sources of eddy kinetic energy in the Labrador Sea. J. Phys. Oceanogr., 32, 3346-3363.

Emery, W., W. Lee, and L. Magaard, 1984: Geographic and seasonal distributions of Brunt-Väisälä frequency and Rossby radii in the North Pacific and North Atlantic. J. Phys. Oceanogr., 14, 294-317.

Falina, A., A. Sarafanov, and A. Sokov, 2007: Variability and renewal of Labrador Sea Water in the Irminger Basin in 1991-2004. J. Geophys. Res., 112, C01006, 10.1029/2005JC003348.

Gascard, J., and K. Mork, 2008: Climatic importance of large-scale and mesoscale circulation in the Lofoten Basin deduced from Lagrangian observations. Arctic-Subarctic Ocean Fluxes, R. R. Dickson, J. Meinke, and P. Rhines, Eds., Springer, 131-143. 
Gourcuff, C., P. Lherminier, H. Mercier, and P. Le Traon, 2011: Altimetry combined with hydrography for ocean transport estimation. J. Atmos. Oceanic Technol., 28, 1324-1337.

Hansen, D., and A. Herman, 1989: Temporal sampling requirements for surface drifting buoys in the tropical Pacific. J. Atmos. Oceanic Technol., 6, 599-607.

— WOCE-TOGA drifter data. J. Atmos. Oceanic Technol., 13, 900-910.

Hátún, H., C. Eriksen, P. Rhines, and J. Lilly, 2007: Buoyant eddies entering the Labrador Sea observed with gliders and altimetry. J. Phys. Oceanogr., 37, 2838-2854.

Hebert, D., N. Oakey, and B. Ruddick, 1990: Evolution of a Mediterranean salt lens: Scalar properties. J. Phys. Oceanogr., 20, $1468-1483$

Holliday, N., A. Meyer, S. Bacon, S. Alderson, and B. de Cuevas, 2007: The retroflection of part of the East Greenland Current at Cape Farewell. Geophys. Res. Lett., 34, L07609, 10.1029/ 2006 GL029085.

— , and Coauthors, 2008: Reversal of the 1960s to 1990s freshening trend in the northeast North Atlantic and Nordic Seas. Geophys. Res. Lett., 35, L03614, doi:10.1029/2007GL032675.

Huppert, H., and K. Bryan, 1976: Topographically generated eddies. Deep-Sea Res., 23, 655-679.

Karstensen, J., 2005: Calibration of physical data. Internal Report Animate Report, Geomar, 43 pp.

Katsman, C., M. Spall, and R. Pickart, 2004: Boundary Current eddies and their role in the restratification of the Labrador Sea. J. Phys. Oceanogr., 34, 1967-1983.

Köhl, A., 2007: Generation and stability of a quasi-permanent vortex in the Lofoten Basin. J. Phys. Oceanogr., 37, 2637-2651.

Krauss, W., 1995: Currents and mixing in the Irminger Sea and in the Iceland Basin. J. Geophys. Res., 100, (C6), 10 851-10 872.

Lavender, K., R. Davis, and W. Owens, 2000: Mid-depth recirculation observed in the interior Labrador and Irminger Seas by direct velocity measurements. Nature, 407, 66-69.

_ , W. Brechner Owens, and R. Davis, 2005: The mid-depth circulation of the subpolar North Atlantic Ocean as measured by subsurface floats. Deep-Sea Res. I, 52, 767-785.

Lherminier, P., H. Mercier, C. Gourcuff, M. Alvarez, S. Bacon, and C. Kermabon, 2007: Transports across the 2002 GreenlandPortugal Ovide section and comparison with 1997. J. Geophys. Res., 112, C07003, doi:10.1029/2006JC003716.

— - — - T. Huck, C. Gourcuff, F. Perez, P. Morin, A. Sarafanov, and A. Falina, 2010: The Atlantic meridional overturning circulation and the subpolar gyre observed at the A25-OVIDE section in June 2002 and 2004. Deep-Sea Res. I, 57, 1374 1391.

Lilly, J., and P. Rhines, 2002: Coherent eddies in the Labrador Sea observed from a mooring. J. Phys. Oceanogr., 32, 585-598.

_ - , F. Schott, K. Lavender, J. Lazier, U. Send, and E. D'Asaro, 2003: Observations of the Labrador Sea eddy field. Prog. Oceanogr., 59, 75-176.

Louarn, E., H. Mercier, P. Morin, E. De Boisseson, and S. Bacon, 2009: Upper Labrador Sea Water in the Irminger Sea during a weak convection period (2002-2006). Ocean Sci. Discuss., 6, 2085-2113.

Martin, J., C. Lee, C. Eriksen, C. Ladd, and N. Kachel, 2009: Glider observations of kinematics in a Gulf of Alaska eddy. J. Geophys. Res., 114, C12021, doi:10.1029/2008JC005231.

Maximenko, N., P. Niiler, L. Centurioni, M. Rio, O. Melnichenko, D. Chambers, V. Zlotnicki, and B. Galperin, 2009: Mean dynamic topography of the ocean derived from satellite and drifting buoy data using three different techniques. J. Atmos. Oceanic Technol., 26, 1910-1919.

McGillicuddy, D., and Coauthors, 2007: Eddy/wind interactions stimulate extraordinary mid-ocean plankton blooms. Science, 316, 1021-1026.

Nelder, J., and R. Mead, 1965: A simplex method for function minimization. Comput. J., 7, 308-313.

Newton, J., K. Aagaard, and L. Coachman, 1974: Baroclinic eddies in the Arctic Ocean. Deep Sea Res. Oceanogr. Abstr., 21, 707-719.

Nilsen, J., and E. Falck, 2006: Variations of mixed layer properties in the Norwegian Sea for the period 1948-1999. Prog. Oceanogr., 70, 58-90.

Picot, N., K. Case, S. Desai, and P. Vincent, 2003: AVISO and PODAAC User Handbook. IGDR and GDR Jason Products, $124 \mathrm{pp}$.

Pingree, R., and B. Le Cann, 1992: Anticyclonic eddy X91 in the southern Bay of Biscay, May 1991 to February 1992. J. Geophys. Res., 97 (C9), 14 353-14 367.

Poulain, P., A. Warn-Varnas, and P. Niiler, 1996: Near-surface circulation of the Nordic seas as measured by Lagrangian drifters. J. Geophys. Res., 101 (C8), 18 237-18 258.

Prater, M., 2002: Eddies in the Labrador Sea as observed by profiling RAFOS floats and remote sensing. J. Phys. Oceanogr., 32, 411-427.

Richardson, P., D. Walsh, L. Armi, M. Schröder, and J. Price, 1989: Tracking three meddies with SOFAR floats. J. Phys. Oceanogr., 19, 371-383.

Rossby, T., V. Ozhigin, V. Ivshin, and S. Bacon, 2009a: An isopycnal view of the Nordic Seas hydrography with focus on properties of the Lofoten Basin. Deep-Sea Res. I, 56, 1955-1971.

$\longrightarrow$, M. Prater, and H. Søiland, 2009b: Pathways of inflow and dispersion of warm waters in the Nordic seas. J. Geophys. Res., 114, C04011, doi:10.1029/2008JC005073.

Rudnick, D., R. Davis, C. Eriksen, D. Fratantoni, and M. Perry, 2004: Underwater gliders for ocean research. Mar. Technol. Soc. J., 38, 73-84.

Rykova, T., F. Straneo, J. Lilly, and I. Yashayaev, 2009: Irminger Current Anticyclones in the Labrador Sea observed in the hydrographic record, 1990-2004. J. Mar. Res., 67, 361-384.

Sarafanov, A., A. Sokov, A. Demidov, and A. Falina, 2007: Warming and salinification of intermediate and deep waters in the Irminger Sea and Iceland Basin in 1997-2006. Geophys. Res. Lett., 34, L23609, doi:10.1029/2007GL031074.

Schmidt, S., and U. Send, 2007: Origin and composition of seasonal Labrador Sea freshwater. J. Phys. Oceanogr., 37, 1445-1454.

Schott, F., R. Zantopp, L. Stramma, M. Dengler, J. Fischer, and M. Wibaux, 2004: Circulation and deep-water export at the western exit of the subpolar North Atlantic. J. Phys. Oceanogr., 34, 817-843.

Sherman, J., R. Davis, W. Owens, and J. Valdes, 2001: The autonomous underwater glider Spray. IEEE J. Oceanic Eng., 26, 437-446.

Stammer, D., and C. Böning, 1992: Mesoscale variability in the Atlantic Ocean from Geosat altimetry and WOCE highresolution numerical modeling. J. Phys. Oceanogr., 22, 732-752.

Talley, L., 1988: Potential vorticity distribution in the North Pacific. J. Phys. Oceanogr., 18, 89-106.

Våge, K., and Coauthors, 2011: The Irminger Gyre: Circulation, convection, and interannual variability. Deep-Sea Res. I, 58, 590-614.

Wolfe, C., and C. Cenedese, 2006: Laboratory experiments on eddy generation by a buoyant coastal current flowing over variable bathymetry. J. Phys. Oceanogr., 36, 395-411. 